\title{
5 Scherzando - Das kommunizierende Gesicht oder die Ehe als Ökonomie der Affekte
}

\subsection{Auftakt}

Auf die Gesichter der Schauspieler wird man in TWENTIETH CENTURY in doppelter Hinsicht aufmerksam. Man sieht echte Schauspieler, die verschiedene Rollen verkörpern: eine Schauspielerin und einen Regisseur. Die Gesichtsausdrücke variieren stark, sind maximal ausdrucksvoll oder gleichgültig. Doch zwischen diesen verschiedenen Darbietungen scheint immer wieder eine subtile Verbindung auf; immer wieder sieht man in den Ausbrüchen von Zorn und Wut, mit welchen sich die Protagonisten in ihrer Auseinandersetzung konfrontieren, zarte Bande, feinste Nuancen von amouröser Hingabe und verdecktem Eros. TWENTIETH CENTURY verquickt das Thema des Schauspielens mit dem Thema menschlicher Bindungs- und Beziehungsfähigkeit. Dabei erscheinen die Gesichter auch abseits der Theaterprobe höchst inszeniert, so als wollte man den Gesprächspartner unbedingt für sich einnehmen: Den traurigen Blick versteht man als Weise, des Anderen Aufmerksamkeit zu erlangen; der Einsatz von Tränen führt zu einer Intensivierung des Gesprächs; die erschrockene Hand am Brustkorb lässt das Gegenüber erschaudern. Das tiefe Raunen von Oscar Jaffe (John Barrymore), mit dem er seine vermeintliche Selbstmordabsicht offenbart, gilt nur etwas, wenn seine Spielpartnerin Lilly Garland (Carole Lombard) darauf auch angemessen reagiert, bestürzt ist, zu ihm eilt oder in Ohnmacht fällt. Man erkennt in den mimischen Interaktionen die Erwartungshaltung des Eitlen, des Selbstbezogenen. Doch das Vorherbestimmte geschieht nicht, Lilly ignoriert seine pathetische Rede und schleicht sich heimlich aus dem Bild. So verpufft die Wirkung seiner pathetischen Gebärde, da sie keinen Widerhall findet. TWENTIETH CENTURY und die anderen Screwball Comedies entwerfen kaum romantische oder sehnsuchtsvolle Bilder. Nicht das subjektive Empfinden steht im Vordergrund, sondern der aufgezeigte, offensichtlich gespielte und kommunizierte Gefühlsausdruck.

In den Screwball Comedies sieht man immer wieder Gesichter der Wut, der Verzweiflung, der Rage und doch scheint sich für den Zuschauer kaum Berührung oder Mitgefühl einzustellen. Standen in den letzten beiden Kapiteln Stimme, Wort und Geste im Zentrum, so geht es in diesem Kapitel um ein weiteres Ausdrucksorgan, um das Gesicht und seine filmische Inszenierung. Dabei wird stärker als in den vorherigen Kapiteln der Zusammenhang 
zwischen Zuschauergefühlen, Gesichtsausdrücken und konstruierten Figurengefühlen erörtert.

\subsection{Das gewöhnliche und das posierende Gesicht}

\section{Alltäglichkeiten in der Screwball Comedy}

Die Ehe mit ihren Mühen und Routinen wird in dem Genrezyklus der Screwball Comedy gewissermaßen zum Sinnbild der Vorstellung von alltäglicher Wiederholung und notwendiger Wiederherstellung gemeinschaftlicher Kompromisse. ${ }^{1}$ In Stanley Cavells Worten wenden sich die Komödien dem Alltäglichen zu: „one’s experience of the everyday“. ${ }^{2}$

It is centrally as a title for these three features of diurnal comedy, the comedy of dailiness - its conclusion not in a future, a beyond, an ever after, but in a present continuity of before and after; its transformation of a festival into a festivity; its correction not of error but of experience, or of a perspective on experience - that I retain the concept of remarriage as the title for the genre of films in question. The title registers, to my mind, the two most impressive affirmations known to me of the task of human experience, the acceptance of human relatedness, as the acceptance of repetition. ${ }^{3}$

Cavell fokussiert mit seiner Beobachtung, dass den Remarriage Comedies (das gleich gilt für den übergeordneten Screwball Zyklus) die Erfahrung einer Gegenwärtigkeit, der Wiederholbarkeit eingeschrieben ist. Die Rituale und Gewohnheiten des ehelichen Alltagslebens werden zur Darstellung gebracht. Die menschliche Bindungsfähigkeit ist an die unvermeidliche Kompromissfähigkeit gebunden. Diese Thematik ist jedoch nicht nur in der dargestellten Handlung der Komödien zu finden, vielmehr gestaltet die Ästhetik der Filme die Zuschauerwahrnehmung im Modus des Alltäglichen.

Dieses Verfahren lässt sich auf der Ebene eines bestimmten Bildtypus fassen. Der Bildtypus, um den es im Folgenden gehen wird, ist an das Gesicht gebunden und ähnlich wie Stimmbild und Paargeste Element der Kommunikation und des Ausdrucksverhaltens, die in den Komödien ansichtig werden. Dabei greife ich (ähnlich wie in den letzten beiden Kapiteln) eine Ausdrucksmodalität des menschlichen Körpers heraus (Gesicht) und beziehe diese auf die filmischen

1 Cavell 1981, S. 15. Vgl. Gertrud Koch: Man liebt sich, man liebt sich nicht, man liebt sich: Stanley Cavells Lob der Wiederverheiratung. In: Texte zur Kunst 13 (2003), H. 52, S. 110-118.

2 Cavell 1981, S. 240. Auch Seeßlen sieht in der in Filmkomödie eine Komik, die „historische und ,alltägliche“ Erfahrungen“ reflektiert. Seeßlen 1976, S. 10.

3 Cavell 1981, S. 240-241. 
Artikulationsformen. Die Tempi der Bewegung sind dabei die Schnittstelle zwischen Schauspiel und filmischer Expressivität.

\section{Das gewöhnliche Gesicht - Neutrale Mimiken und die Nachkommenschaft Kuleschows}

Jacques Aumont hat in seiner Studie eine ästhetikgeschichtliche Typologie von Gesichtsbildern im Film entwickelt. ${ }^{4}$ Sein Blick auf das Schauspiel ist dabei nicht allein auf die verschiedenen Schauspielstile gerichtet, sondern immer schon auf die filmische Inszenierung bezogen und als historische Analyse der je spezifischen Filmästhetik zu lesen.

Die Inszenierung mimischer Bilder im US-amerikanischen Erzählkino der 1930er und 1940er Jahre beschreibt er mit dem Bildtypus des gewöhnlichen Gesichts. ${ }^{5}$ Der Bildtypus leitet sich vom Kuleschow-Effekt ab, der seine Nachkommenschaft in der Découpage des klassischen Hollywood-Kinos entfaltet. ${ }^{6}$ Das gewöhnliche Gesicht als neutrale und reaktive Mimik sei gerade das Gegenteil des Affekt-Bilds bei Deleuze sowie seines historischen Äquivalents, dem expressiven Stummfilm-Gesicht. ${ }^{7}$ In der Konzeption des gewöhnlichen Gesichts wird für Aumont die Aussage Hitchcocks zentral, er habe seine Schauspieler für eine Groß- oder Nahaufnahme dazu angehalten, ausdruckslos zu blicken. ${ }^{8}$ Hitchcock erklärt im Interview mit Truffaut sein Vorgehen als inszenatorisches Mittel zur optimierten Kontrollfunktion durch den Regisseur:

Meiner Meinung nach muß der Schauspieler im Film entschieden schmiegsamer sein, eigentlich braucht er überhaupt nichts zu machen. Er muß ein ruhiges und natürliches Benehmen haben, was übrigens gar nicht so einfach ist, und er muß es hinnehmen, daß er

4 Er differenziert dabei in vielerlei Hinsicht das Affektbild von Deleuze aus. Während Deleuze sowohl eine Taxonomie der Bildtypen entwickelt als auch eine Geschichte des filmischen Denkens schreibt, ist es Aumont daran gelegen, die Abbildung und Präsentation des menschlichen Gesichts in einen historisch-ästhetischen Zusammenhang zu bringen. Vgl. Aumont 1992.

5 „la face ordinaire“, vgl. Jacques Aumont: Das Un-Gesicht. In: Jürgen E. Müller und Markus Vorauer (Hg.): Blick-Wechsel. Tendenzen im Spielfilm der 70er und 80er Jahre. Münster 1993, S. 215-222.

6 Siehe Aumont 1993, S. 217. Siehe auch Aumont 1992, S. 48-49.

7 Aumont 2003, S. 146.

8 Das Zitat Hitchcocks ist bei Aumont nicht extra aufgeführt, sondern wird nur paraphrasiert. Aumont 1993, S. 217. 
benutzt und vom Regisseur und der Kamera in den Film eingebaut wird. Er muß es der Kamera überlassen, die besten Akzente und die besten Höhepunkte zu finden. ${ }^{9}$

Damit setzt Hitchcock den Status des Schauspiels deutlich herab. Der Darsteller wird für ihn zum materiellen Grund, auf dessen Basis die filmische Inszenierung gestalterisch eingesetzt werden kann. Er hebt die Ausdrucksmöglichkeiten der Kamera hervor, die er personalisiert, da er sie in einem Zug mit dem Regisseur nennt.

Ganz ähnlich wird das neutrale Schauspiel des Kuleschow-Effekts beschrieben. ${ }^{10}$ In der mimischen Praxis einer Neutralität vor der Kamera verschiebe sich, so Pascal Bonitzer, die Expressivität vom Schauspielerkörper auf die Montage:

What was involved [in the Kouleshov-effect, Anmerkung sg] was in some way a third stage, a reduction of acting to its zero degree, so that its powers might be delegated to editing alone, to the auteur. Gesture, concentration [...] and neutrality would thus represent three stages in a progressive domestication of the actor's body [.. .]. ${ }^{11}$

Während Hitchcock von der Verbindung zwischen Kamera und Regisseur spricht, nennt Bonitzer für den Kuleschow-Effekt die Montage und den Auteur als interagierende Partner. Das Gesicht tritt in der klassischen Découpage nicht mehr in seiner Einzigartigkeit prominent hervor, sondern wird zum Bestandteil unter vielen. Aumont begreift Hitchcocks einflussreich gewordenes Diktum von der neutralen Mimik folgendermaßen:

Die bewusste Inexpressivität sollte den leichten Übergang von einer Einstellung zur nächsten gewährleisten, ohne daß das Gesicht Widerstand leistete, ohne daß es haften blieb. $^{12}$

Das gewöhnliche Gesicht bestimmt Aumont demnach als tendenziell inexpressiv, neutral und transparent, es sei darauf ausgerichtet, von Einstellung zu Ein-

9 Hitchcock in François Truffaut: Mr. Hitchcock, wie haben Sie das gemacht? (1973/ 1966). München 2003, S. 101.

10 Das Experiment wird beschrieben von Wsewolod Pudowkin: Das Modell anstelle des Schauspielers (1929). In: ders.: Die Zeit in der Großaufnahme. Aufsätze, Erinnerungen, Werkstattnotizen. Berlin 1983, S. 355.

11 Pascal Bonitzer: Hitchcockian Suspense. In: Slavoj Žižek (Hg.): Everything You Always Wanted to Know about Lacan (but Were Afraid to Ask Hitchcock). London/New York 1992, S. 15-30, hier: S. 17.

12 Aumont 1993, S. 217. 
stellung überzugehen. ${ }^{13}$ Daher steht es auch nicht für sich, verweist nicht auf sich zurück, nicht auf seine Individualität, vielmehr sei es zirkulär und austauschbar. ${ }^{14}$ Die Beschaffenheit des Gesichts fasst Aumont als Oberfläche, welche den Sinn anderer Bilder aufnehme und sich selbst wiederum in andere Bilder einschreiben könne. ${ }^{15}$ Die Gesichtsbilder wechselten sich im klassischen Hollywood-Kino vor allem im Bezug auf ein narratives Geschehen ab, so dass sich alle Elemente der Erzählung unterordnen. ${ }^{16}$ Dass diese im Erzählkino funktional im Hinblick auf die Handlung seien, ist kein neues Argument. Doch Aumont setzt dies in Verbindung mit audiovisuellen Bildformen und filmischer Expressivität.

Er ordnet den verschiedenen Gesichtsbildern ökonomische Prinzipien zu - im marxistischen Vokabular: Im Gegensatz zum ,Gebrauchswert' des Stummfilmgesichts, dessen Ausdruck an das einzelne Gesicht, an die Dauer und Intensität der mimischen Regung gebunden ist, stellt sich das Gesicht in der Kontinuitätsmontage des klassischen Films durch das Prinzip des Tauschs dar. ${ }^{17}$ Ökonomische Prinzipien bestimmen nicht nur Hollywoods Filmproduktion mit ihren zerlegten Arbeitsprozessen, sondern werden auch in den Filmen selbst reflektiert. ${ }^{18}$ Ist die Automatik von Fließband und Maschine u.a. ein Bezug für Slapstick und Komödie rund um das Thema Arbeit (z.B. in MODERN TIMES), so wenden sich die Screwball Comedies mit pragmatischem Blick den Tauschbeziehungen im zwischenmenschlichen Alltagsleben zu, in Ehe, Freundschaften, Familie, Arbeitsbeziehungen. ${ }^{19}$ Die Gesichter treten im klassischen Kino funktional in Bezug auf das Erzählte auf, werden eigens zu Mitteln eines Tauschs innerhalb der Bildästhetik.

So ist das Gesicht, wie Aumont schreibt, generell der „Ort von sozialen, interpersonellen und intersubjektiven Funktionen, der Ort der Kommunikation (der Höflichkeit, der Konversation, des höfischen Diskurses), der Ort der Expression“20. Die Expressivität des gewöhnlichen Gesichts liegt nicht im individuellen Ausdruck,

13 „[C]omme jeton du jeu sémiotique“, Aumont 1992, S. 48.

14 „,U]ne figure toujours échangeable contre d'autres figures“, Aumont 1992, S. 48.

15 Aumont 1992, S. 49; Aumont 2004, S. 27.

16 Aumont 1992, S. 49, S. 59.

17 „[L]a valeur d'échange“, Aumont 1992, S. 48. „[U]n pur opérateur de sens, de récit et de mouvement“, ebd., S. 49.

18 Vgl. Cavell 1981, S. 5. Deleuze sieht das Prinzip ökonomischer Sparsamkeit als mit den Ästhetiken des Bildes verbunden, so etwa im Aktionsbild der kleinen Form angesiedelt, in den B-Movies oder Komödien, dem Detektivfilm des klassischen Hollywood-Films etc. Deleuze 1997 (1983), S. 220.

19 Seeßlen 1976, S. 49.

20 Aumont 1993, S. 217. 
sondern zwischen den Einstellungen, im Zirkulieren der Bilder. ${ }^{21}$ Die Ausdruckskraft beruht in der Interaktion, im Austausch der Bilder, auf dem sich gegenseitigen Berühren, dem sich Einschreiben einer Einstellung in die nächste. Das einzelne Antlitz ist - für sich genommen - vage, ambigue, mehrdeutig, es ist immer schon auf etwas anderes ausgerichtet, auf ein zweites Bild, einen Gegenstand, auf ein zweites Gesicht. ${ }^{22}$ Erst in einer Relation entwickelt sich sein Sinn.

Mit dieser Bestimmung des Bildtypus des gewöhnlichen Gesichts hat Aumont das Aktionsbild der kleinen Form nach Deleuze enggeführt. Wenn Deleuze davon spricht, dass das Affektbild gerade nicht das ist, was man mit dem Gesicht üblicherweise in einer alltäglichen Vorstellung verbindet (z.B. die Individualität) ${ }^{23}$, dann kann man genau von einer solchen montagebedingten Aufladung des Gesichts im Aktionsbild sprechen: Im Aktionsbild aktualisiert sich das Gesicht in seinen Bezügen, wird Kommunikationsmittel, wird einer sozialen Gruppe zuschrieben, wird einer Figur zugeordnet, ihren Motivationen, den Handlungen und einer diegetischen Welt, die nicht mehr beliebig, nicht mehrdeutig sind. Das damit verbundene Prinzip einer Verbindung von Objekt und Gefühl fasst Deleuze als grundlegenden Mechanismus für die Fiktionsbildung auf. An die Objekt/GefühlBeziehung sei die ,sichtbare Verkettung von fiktiver Situation und erfundener Handlung“24 gebunden:

Das Paar Gegenstand/Gefühl erscheint also im Aktionsbild als dessen genetisches Zeichen. Der Gegenstand wird in allen seinen Virtualitäten erfaßt (als gebrauchter, verkaufter, gekaufter, getauschter, zerbrochener, geküßter, abgelehnter...) während sich zugleich die entsprechenden Gefühle aktualisieren [.....$^{25}$

Mit diesem Verhältnis werden die Gefühle dinglich vergegenwärtigt, welche die Situation aufrufen (zerbrochen, geküsst, abgelehnt). Die Anordnung von Gegenstand und Gefühl, welche Deleuze für das „Kino des Verhaltens““26, für das klassische

21 „[L]e fait que le visage, affecté par son voisinage, acquiert de l'expression.“ Aumont 1992, S. 49. Oder: „Ce visage est fait pur faire passer, pour émettre et, corrélativement, pour recevoir." Ebd., S. 51. Dabei spricht er die Stimme und den Blick (Vektorisierung) als weitere Aspekte des gewöhnlichen Gesichts an, die ebenfalls das kommunikative Geschehen unterstützten, ebd., S. 50-55.

22 Diese Vorstellung vom Gesicht, das sich immer nur im Bezug zu einem anderen Bild, einer anderen Mimik herstellt, leitet sich von Deleuzes Begriff des Aktionsbilds (als Zweitheit) ab. Deleuze 1997 (1983), S. 193-195.

23 Die Wirkung der Großaufnahmen ist, dass sie „die Individuation, ebenso wie die Sozialisation oder Kommunikation verloren“ haben. Deleuze 1997 (1983), S. 140.

24 Deleuze 1997 (1983), S. 215.

25 Deleuze 1997 (1983), S. 216.

26 Deleuze 1997 (1983), S. 215. Die Komödien z.B. von Lubitsch, welche sich als Aktionsbild der kleinen Form ausprägen, erinnern an eine Art Verhaltensexperiment („Kino des 
Hollywood-Kino als konstitutiv proklamiert, wird bei Aumont im Bezug auf das Gesicht zum einen verschärft, aber auch in sein Gegenteil verkehrt. Deleuze geht davon aus, dass für das Aktionsbild tendenziell die Regel des Actor's Studios vorherrschend ist („nur das, was innen ist, zählt“27), so dass der Schauspieler in seinem Spiel einen Gegenstand mit seinem Gefühl aufladen müsse, dass er dann mit diesem Gegenstand dieses Gefühl zu aktualisieren vermag. Freilich ist dies für Deleuze nur Ausgangspunkt der Überlegungen, diese Aktualisierung sieht er grundsätzlicher an der Zweitheit der Bilder ausgerichtet. Mit Aumont mag man die Anordnung von Gegenstand und Gefühl als umgedreht betrachten, wenn er für das gewöhnliche Gesicht die Schauspiel-Maxime von Spencer Tracy erläutert: Es sei für ihn die einzige Methode, seinen Text $\mathrm{zu}$ wissen und $\mathrm{zu}$ vermeiden, die Möbel oder die anderen Schauspieler anzurempeln. ${ }^{28}$ Das Schauspiel wird so maximal ausdruckslos, neutral, eine physische Materie, die man unterschiedlich einsetzen kann (nur das, was außen ist, zählt). ${ }^{29}$ Beide Überlegungen überschneiden sich in der Idee von einer Relationalität (im Binom bzw. dem Tauschwert).

Deleuze schreibt: „Nicht etwa daß der Verhaltensfilm unbedingt die Großaufnahme vermiede [. . .]. Trotzdem kann der emotionale Umgang mit einem Gegenstand, ein Gefühlsakt gegenüber einem Gegenstand, mehr Wirkung erzielen als eine Großaufnahme im Aktionsbild.“30 Diesen Gedanken spezifiziert Aumont, indem er aufzeigt, dass das Gesicht im klassischen Kino selbst gegenständlich eingesetzt werden kann. Der Affekt ist in einer solchen Konstellation jedoch nicht inexistent, vielmehr verschiebt er sich (vom Schauspiel zum Gegenstand) auf das Schauspiel als Gegenstand: auf die Montage. Die Konsequenz ist eine radikale Äußerlichkeit als Maxime auf der Ebene des Einzelgesichts. Die Ausdrucksbewegung liegt in den Austauschverhältnissen der verschiedenen Einstellungen von Gesichtern im Wechsel, in der changierenden Bezugnahme.

Der Bildtypus des gewöhnlichen Gesichts lässt sich an einer Szene aus MR. AND MRS. SMITH ${ }^{31}$ zeigen. Man sieht zunächst die Eheleute von der Seite am

Verhaltens,“ ebd.), das man in seinem Dualismus beobachten kann. Im Falle des Binoms als besondere Variante des Aktionsbilds ist damit eine duell-ähnliche Situation beschrieben, „wenn ein bestimmter Kräftezustand auf eine entgegengesetzte Kraft verweist.“ Ebd., S. 195.

27 Deleuze 1997 (1983), S. 15.

28 ,[L]a seule méthode: savoir son texte et éviter de se cogner dans les meubles et les autres acteurs“, Aumont 1992, S. 47.

29 Pudowkin beschreibt das so: „Ich glaube, die entscheidende Gefahr für den, der vor der Filmkamera steht, ist es - wie man so sagt - ,schauspielerisch zu spielen'. Ich möchte nur mit realem Material arbeiten [...]. Ich habe versucht mit Menschen zu arbeiten, die noch niemals eine Bühne oder einen Film gesehen hatten.“ Pudowkin 1983 (1929), S. 356.

30 Deleuze 1997 (1983), S. 216.

31 TC: 0:06:55-0:09:44. 
Frühstückstisch sitzen. David Smith (Robert Montgomery) und Anne Smith/ Krausheimer (Carole Lombard) sitzen am Tisch, einander gegenüber. Die Einstellung zeigt das Paar in symmetrischer Anordnung von der Seite (Abb. 29).

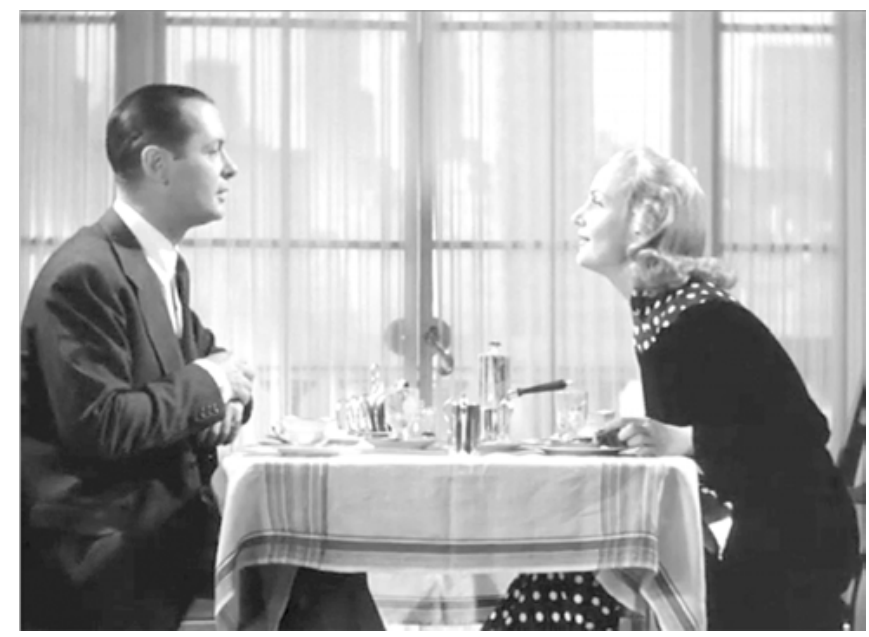

Abbildung 29: Szene am Frühstückstisch - MR. AND MRS. SMITH.

Mit dem Einsetzen der Schuss-Gegenschuss-Montage und den Nah- oder Großaufnahmen entspinnt sich eine Unterhaltung, welche innerhalb der filmischen Inszenierung um zwei reaktive Mimiken kreist. Dabei ist der Gegenstand des Gesprächs nicht allein der Inhalt der Worte als der Wechsel einer geteilten Stimmung, die von friedlich über insistierend, von bemüht zu enttäuscht, beleidigt übergeht. Die Stimmung wird dabei hauptsächlich durch den Wechsel des gewöhnlichen Gesichts in der Schuss-Gegenschuss-Montage evoziert. Hierbei ist anzumerken, dass die Gesichter nicht durchweg ausdruckslos, sondern nur tendenziell neutral sind. So gibt es durchaus mimische Regung, doch diese werden vom Schnitt unterbrochen, dürfen sich nicht entfalten (Abb. 30).

Die Mimiken beider Schauspieler werden jeweils als reaktiver Teil auf das bisher Gesehene und Gehörte dargestellt. Kein Blick steht für sich, nur in der Montage konstituieren die mimischen Regungen sich als Affekte. Die Einheit beschreibt anfangs einen oszillierenden Schnitt- und Sprechrhythmus, der zunächst ein langsames Hin und Her ist, dass sich dann durch die Stimmklänge beschleunigt und dann auf einem Plateau gehalten wird. Hierauf folgen Nahaufnahmen. Man sieht Montgomerys ausdrucksloses Gesicht, in das sich Lombards Frage einzuschreiben scheint: „Remember rule number seven?“. 

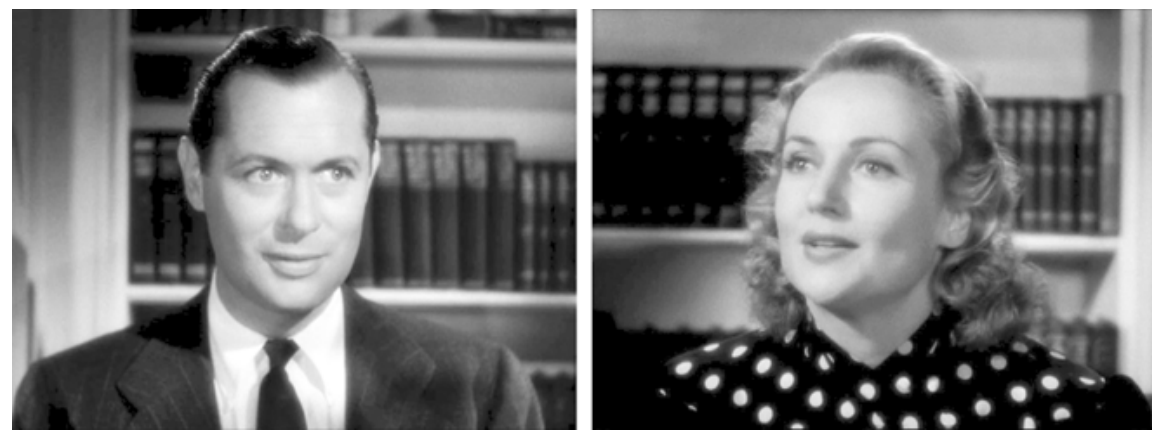

Abbildung 30: Der Wechsel aufeinander bezogener Mimiken - MR. AND MRS. SMITH.

Die Bildform des gewöhnlichen Gesichts ist nicht rein visuell, vielmehr leitet sie sich von der im Drehbuch vorgegeben Dialogizität ab. Aumont sagt: „The ordinary face communicates, it can even seduce, but its role is to disseminate words, words of order.“32 Das Wort und die Stimme sind demnach Teil seines kinematografischen Verbunds:

Das gewöhnliche Gesicht ist der Moment der wahrscheinlich makellosen Einheit zwischen Mund, Wort und Stimme, aber unter der Rute des Wortes. ${ }^{33}$

Der Vokonzentrismus ist demnach eng mit dem gewöhnlichen Gesicht verbunden. ${ }^{34}$ In der Szene beginnt nun ein neuer Wechsel, Nahaufnahmen werden in schnellerer Abfolge innerhalb des Gespräch dargeboten. Damit verbunden sind stärkere reaktive Bewegungen innerhalb der Mimiken beider Schauspieler (Abb. 31).

Montgomery zieht seine Stirn in Falten, seine Augen blicken klar und hell auf sein Gegenüber. Zur erklärenden, verdeutlichenden Mimik kommt sein rechtfertigender Satz zu implizit gelassenen Verfehlungen seinerseits: „I was only twenty-one“ - Lombard reagiert mit sanftem Blick und im Stimmklang der Großzügigkeit (große Bögen), indem sie sich leicht lächelnd nach vorne beugt: „Oh, I forgave you that!“. Abweisung und Annäherung im Zwischenmenschlichen sind dabei über eine subtile Dramaturgie der Aufnahmedistanzen in Szene gesetzt. Die Kadrierung nähert sich an die Gesichter an, wenn sie ihn fragt, ob er sie heute

32 Aumont 2003, S. 140.

33 Übersetzung: sg, Aumont 1992, S. 51.

34 Siehe Kapitel 3 zur Stimme. 

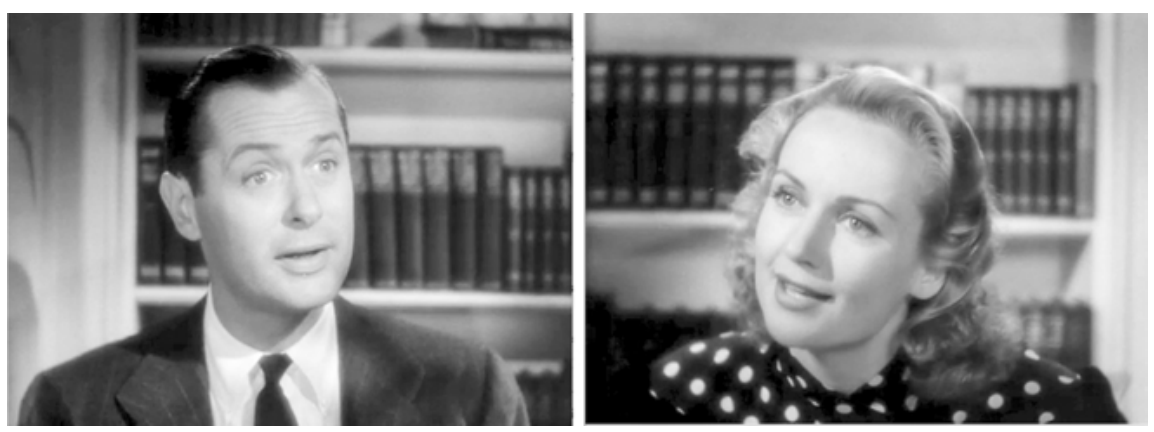

Abbildung 31: Stärkere Gesichtsbewegungen im tendenziell ausdrucksreduzierten Spiel - MR. AND MRS. SMITH.

trotz allem noch einmal heiraten würde. Und der Kader distanziert sich, wenn er darauf mit „no“ antwortet. Wie als Reaktion auf seine Zurückweisung bleibt die Einstellung dann ungewöhnlich lange auf Lombards Gesicht, das jedoch ohne große Regungen auskommt. Vielmehr so scheint es das Prinzip der Filme zu sein, ist die Montage Teil des Gesprächs. Der Kader beantwortet Montgomerys Satz mit einem verharrenden, dauernden Blick auf die Schauspielerin.

Das gewöhnliche Gesicht lässt keine individuellen Gefühle erkennen, sondern konstituiert Affekte durch die Montage, wobei ein kommunikatives Spiel der Abhängigkeiten und Launen sichtbar wird, welches bindende und begrenzende Kräfte einer Paardynamik anschaulich macht. Damit gehen Funktionen des alltäglichen Sprechens einher, das von einer Sekunde zufriedener Harmonie in kühle Distanz sich zu wenden vermag. „I'm not angry in the least“ sagt Lombard mit gezwungenem Lächeln. Das zwischenmenschliche, kommunikative Verhältnis selbst ist durch die Schuss-Gegenschuss-Montage ausgedrückt: Für die Schwingung zwischen zwei Personen wird kinematografisch ein Bild gefunden, feinste Nuancen der Aufeinanderbezogenheit, subtilste Reaktionen von Wohlwollen, Eigensinn oder Kränkung werden sichtbar, ohne dass dies an einem einzelnen Gesicht festzumachen wäre.

Die Komik der Szene liegt auch in der abwechselnden Lächerlichkeit, mal erlebt man Annes Insistieren auf den Spielregeln ihrer Ehe als übergriffig und herrisch, dann wieder sieht man Davids brüske Zurückweisung als emotionale Entgleisung. Die Paaransicht (symmetrisch gestalteter Establishing-Shot und darauffolgender Schuss-Gegenschuss-Wechsel) begünstigt jedoch ein stetes Ausgleichen dieser Einzelmomente, die bildlich in der Waage gehalten werden. Es ist die Offenheit des gewöhnlichen Gesichts, welche die Zuschauer fesselt; dies bereitet Vergnügen. Denn so ist Davids Antlitz wie eine beschreibbare Fläche; Anstöße (ihre Worte) und Anregungen (ihre Blicke) verändern es und in Annes Mimik sammeln 
sich seine Stimmmelodien als Schwingungen; Es sind die Responsivität und die Abhängigkeit der Gesichter voneinander, welche exakt die Geschehenisse der Szene zur Darstellung bringen.

Das Inexpressive an den einzelnen mimischen Regungen ist, dass sie allein keinen Sinn ausbilden, dafür sind die einzelnen Einstellungen viel zu kurz. Die subtilen Veränderungen im Antlitz bilden Entsprechungen zu der vorherigen Einstellung aus, sind fein gesponnene match cuts, welche weit mehr erzeugen als technische Bildanschlüsse oder visuelle Kontinuität. Sie machen vielmehr Resonanz, Intersubjektivität, das Wollen, den Wunsch des einen im Gesicht des anderen sichtbar. Das einzelne Gesicht wird durch die Tauschfunktion Träger vorhergegangener Blicke, in seine Oberfläche schreiben sich Zustimmungen oder Unvernehmen vorheriger Wechsel ein und so stellt sich durch die Montage eine feingliedrig oszillierende Spannung her, die Eigendynamiken der Paarbeziehung zwischen Bindung und Freiheit als kinematografische Anschauung entwickelt.

Verbinden sich im Affektbild Gesichtsausdruck und Großaufnahme in einer Dauer, so ist das gewöhnliche Gesicht als Zusammenhang von reaktiver Mimik und Schuss-Gegen-Schuss-Prinzip in kurzen Einstellungen zu charakterisieren, ob nun die Einzelgesichter in Nah- oder Großaufnahmen angelegt sind.

Doch zu dem gewöhnlichen Gesicht tritt ein Gegenspieler; neben den fließenden Montagen, in denen die Mimik nicht haften bleibt bzw. jeweils tendenziell inexpressiv gehalten ist, weisen die Komödien eine zweite Form des Gesichtsbilds auf: das posierende Gesicht.

\section{Masken und Grimassen - Das posierende Gesicht}

War in Aumonts Konzept die Unauffälligkeit mimischer Bewegungen, das Zurücktreten und die Neutralität des Schauspiels zentral, so stellt sich eine andere Facette des Gesichts in den Komödien in den Zusammenhang des Tauschwerts. Auch der Wechsel eines neutralen Gesichtsausdrucks zur Pose bestimmt die Ästhetik der Screwball Comedies. Dieser Aspekt geht deutlich über Aumont hinaus: Es ist der rhetorische Einsatz von Gesichtsausdrücken, die sich als Grimassen, Maskeraden, basisemotionale Displays und zeichenhaft gewordene Bewegungen in den Filmen finden lassen.

Das posierende Gesicht ist an den sozialen Ritus gebunden, es geht - um mit Erving Goffman zu sprechen - darum, “das Gesicht zu wahren, um nicht das 
Gesicht zu verlieren". ${ }^{35}$ Goffman erläutert es mit der Schilderung der Gemeinschaft der Shetland-Insulaner:

Kam ein Nachbar auf eine Tasse Tee zu Besuch, dann zeigte er meist wenigstens andeutungsweise ein erwartungsvolles Lächeln, wenn er die Kate betrat. Da man aber, weil nichts die Sicht versperrte und es in der Kate verhältnismäßig dunkel war, den Besucher schon, während er sich noch dem Haus näherte, unbemerkt beobachten konnte, sahen die Inselbewohner gelegentlich mit Vergnügen, wie der Besucher erst beim Eintreten eine gesellige Miene aufsetzte. Einige Besucher jedoch, die darüber Bescheid wußten, nahmen auf gut Glück schon in großer Entfernung vom Haus einen geselligen Gesichtsausdruck an und sicherten so, daß ihr Bild in den Augen der anderen konstant blieb. ${ }^{36}$

Die von Goffman angesprochene Praxis des mimischen Spiels als bewusst eingesetzte, soziale Verhaltensform zeichnet die ästhetische Praxis des posierenden Gesichts in der Screwball Comedy gut nach. Dabei werden die „gesellige Miene“37 und andere Posen oft in Szenen eingesetzt, in denen man als Zuschauer das Gespielte, die intendierte Ausdruckskontrolle durch die fiktionalisierten Figuren erkennt. Die Emotionsausdrücke, die sichtbar werden, sind innerhalb der Diegese oftmals als eindeutig gespielt und überzeichnet bewertbar, sie sind meinend (im Sinne Plessners ${ }^{38}$ ); ähnlich dem gewöhnlichen Gesicht werden die Verlaufsformen des mimischen Ausdrucks nicht in einer Dauer ausgestellt, sondern die Gesichtsausdrücke wechseln sich rasch ab, werden zu funktionalen Aktanten des voranzutreibenden Streitgesprächs. Mikrobewegungen, wie das Heben einer Augenbraue, erhalten so etwa den Status von instrumentell einsetzbaren Argumenten.

Das posierende Gesicht lässt sich am besten als Gegenspieler zum gewöhnlichen Gesicht begreifen. Ist das neutrale Antlitz eine Oberfläche, welche die anderen Bilder verbindet, mit ihnen kommuniziert, seine eigene Expressivität an die Montage abtritt, dann ist das posierende Gesicht das eruptive und verstörende Element in diesem Gefüge. Die mimischen Darstellungen sind, ähnlich wie Arnheim im Hinblick auf den Stummfilm schreibt, „,peinlich vergröbert“; ${ }^{39}$ jede Regung bekommt eine eindeutige muskuläre Entsprechung. ${ }^{40}$ Gewährleisteten die sprechenden Münder und neutralen Blicke des gewöhnlichen Gesichts

35 Erving Goffman: Interaktionsrituale. Über Verhalten in direkter Kommunikation. Frankfurt a. M. 1971, S. 14. (Kursivierung durch sg)

36 Erving Goffman: Wir alle spielen Theater. Die Selbstdarstellung im Alltag (1969). München 2005, S. 11-12.

37 Goffman 2005 (1969), S. 11-12.

38 Plessner 2003 (1945), S. 260.

39 Arnheim 1979 (1932), S. 176.

40 „Mimische Standards“ seien laut Löffler ein Teil der Filmdebatte um den Schauspielerkörper und die kinematografischen Mittel in den 1920ern gewesen. Löffler 2004, S. 248-249. 
einen glatten Fluss in der Montagebewegung, so bricht das posierende Gesicht diesen auf, sticht hervor bzw. bleibt haften. Es ist jedoch ebenfalls in seiner Ausrichtung auf ein zweites Bild zu verstehen: es kommuniziert. So mag das Gesichter- und Grimassenschneiden zunächst verstörend wirken, es wird jedoch immer wieder in einen kontinuierlichen Fluss überführt.

So spiegeln sich die Gesichter Lombards und Barrymores in TwENTIETH CENTURY, in dem Lombard ihr Gesicht zu einer Schnute zusammenzieht und darauf Barrymores angestrengtes Nachahmen dieser Schnute zu erkennen ist (Abb. 32). ${ }^{41}$
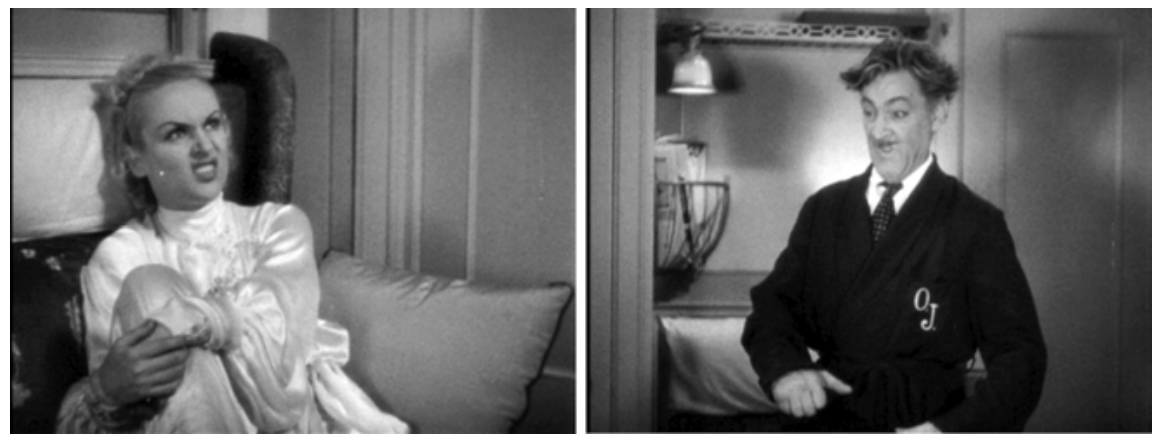

Abbildung 32: Grimassieren und Posieren - TWENTIETH CENTURY.

Doch die grimassierenden Gesichter sind nicht allein in der theatralen Herausstellung ihrer Künstlichkeit eindeutig. Andere Ausprägungen der Pose sind oftmals narrativ eingebunden, so dass sie nicht als Selbstzweck erscheinen, sondern durch ein Rollenspiel motiviert sind. So etwa Irene Dunnes Tanz in THE AWFUL TRUTH, wenn ihre aufgesetzten Gesichtsausdrücke und übertriebenen Gesten in zweckhafter Ausrichtung verstanden werden, nämlich als Strategien, um ihren Exmann vor der Familie seiner Verlobten lächerlich zu machen, um ihn zurückzugewinnen. Die Pose ist also mal einfache Performance und Spiel, mal strategisch eingesetzte Waffe.

Das gewöhnliche und das posierende Gesicht beziehen sich auf einen inhärenten Widerspruch der Komödien, dass es nämlich alltägliche Szenerien und Exzentrik, das Normale und das Aus-der-Rolle-fallen gibt. Auf dieser Ebene werden soziale Codes, gesellschaftliche Regeln und Normen sowie ein Ausbrechen daraus erfahrbar. Die Screwball Comedy als Gesellschaftskomödie lässt sich genau

41 TC: $1: 07: 17-1: 14: 33$. 
auf dieser Ebene fassen, sie erzählt nicht allein von Gruppen, Paaren, Liebesund Arbeitsbeziehungen, sondern kreiert Imaginationen und Reflexionen über Gemeinschaftspraktiken, soziale Verhaltensnormen und Geschlechterbeziehungen. Beide Formen - das gewöhnliche und das posierende Gesicht - verbinden sich in einem Punkt, nämlich im Hinblick auf ihre Kommunikationsfunktion und die zeitliche Gestaltung. Entwickelt Deleuze das reflektierende und das intensive Gesicht als die verschiedenen Pole des Affektbilds, dann verwandeln sich diese fazialen Formen in der Komödie zum gewöhnlichen und posierenden Gesicht. ${ }^{42}$ Die affektive Dimension ist beim gewöhnlichen und posierenden Gesicht in der Montage angesiedelt (und nicht davon ablösbar).

\section{Gesichtscollagen in THE PHILADELPHIA STORY}

Auch in Gruppen-Bildern der Komödien hat das Gesicht die Funktion, zu kommunizieren. So sind etwa in THE PHILADELPHIA STORY häufig extrem verschiedene Gesichtsausdrücke in einer Einstellung zu finden. In solchen Gesichtscollagen kommen posierende Gesichter mit unterschiedlichem Emotionsausdruck zueinander, die Kommunikation erfolgt synchron oder abwechselnd. Man erfährt einander widersprechende, zugespitzte Ausdrucksmuster (Abb. 33).

In einer Einstellung sieht man Onkel Willie (Roland Young), die Mutter (Mary Nash) und Tracy (Katharine Hepburn). Dabei divergieren die beiden Gesichtsausdrücke der Frauen, ein Umstand, den man als Zuschauerin als dargestellte Emotion der einzelnen Figuren zu bewerten vermag. Tracy jubiliert über einen weiteren Komparsen in ihrer Aufführung. Die Mutter blickt voller Bangen. Tracy ergreift sofort die Initiative und setzt ein gespieltes Lächeln auf. Das ängstlich erschaudernde Gesicht der Mutter ist direkt neben das euphorisch-freudige Gesicht Katharine Hepburns gestellt. Tracys Ausgelassenheit überdeckt die Befürchtung der Mutter. Durch die Kontrastierung verschiedener Affektausdrücke nicht nur im Schuss-Gegenschuss, sondern auch in einer Einstellung als Gruppenansicht, hebt sich der individuelle Gesichtsausdruck in gewisser Weise auf, wird kontextualisiert, neutralisiert und relativiert.

42 Kappelhoff und Greifenstein 2014. 


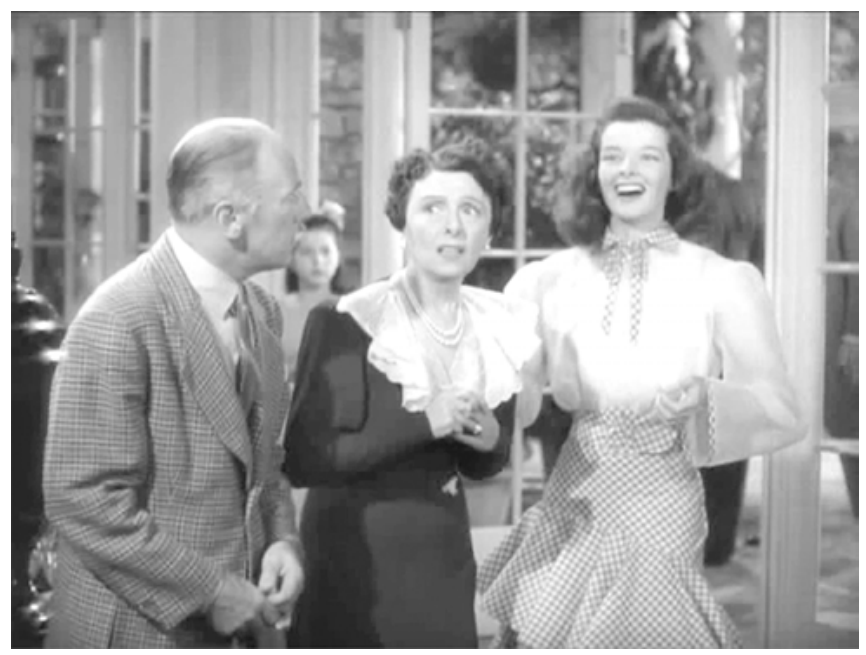

Abbildung 33: Kontrastive mimische Ausdrucksmuster in THE PHILADELPHIA STORY.

\section{Das Fotografiergesicht - THE PHILADELPHIA STORY}

In derselben Szene, wenig vorher, geht es wiederum um das Posieren, diesmal aber unter dem narrativen Deckmantel des Fotografiergesichts. ${ }^{43}$ Die Sorge vor dem Aufdecken von privaten Angelegenheiten und Geheimnissen steht hier im Zentrum des Rollenspiels, in dem jeder von der Figur Tracy eine eigens erfundene Rolle zugeschrieben bekommt. Man spielt gegen eine mögliche zukünftige Peinlichkeit an: Jede traute Geste, jeder ausgetauschte Blickwechsel könnte von den Journalisten festgehalten, falsch ausgelegt und veröffentlicht werden (Abb. 34).

\footnotetext{
43 Dazu merkt Cavell an, dass der Film selbst das Fotografieren als Akt behandelt. Am Ende des Films, als Tracy und Dexter vor dem Traualtar stehen wandelt sich das bewegte Bild in ein Standbild, während die Schauspieler vor Überraschung wie ertappt sind, als hätte jemand einen Schnappschuss gemacht, blicken sie in die Kamera. Da schreibt sich in das letzte Bild nicht nur die vorhergegangene Auseinandersetzung mit dem Journalismus als Spannung zwischen Öffentlichen und dem Privaten ein, sondern auch der Zuschauerblick. Stanley Cavell: The Philadelphia Story/Die Nacht vor der Hochzeit. In: Stanley Cavell: Cities of Words. Ein moralisches Register in Philosophie, Film und Literatur. Zürich 2010 (Legierungen. Bd. 7), S. 65-78, hier: S. 71. Darüber hinaus reflektiert der Film als Ganzes das Festgeschrieben werden im Foto als gesellschaftliches Rollenbild. Am Ende des Films fixiert das Bild die Paareinheit vor dem Traualtar als ironisches Bild eines „in alle Ewigkeit“. Fotografie und Ehe werden zusammengeführt. Das Fixieren im Foto und das Jawort gehen zu schnell, die beiden Figuren werden überrumpelt.
} 


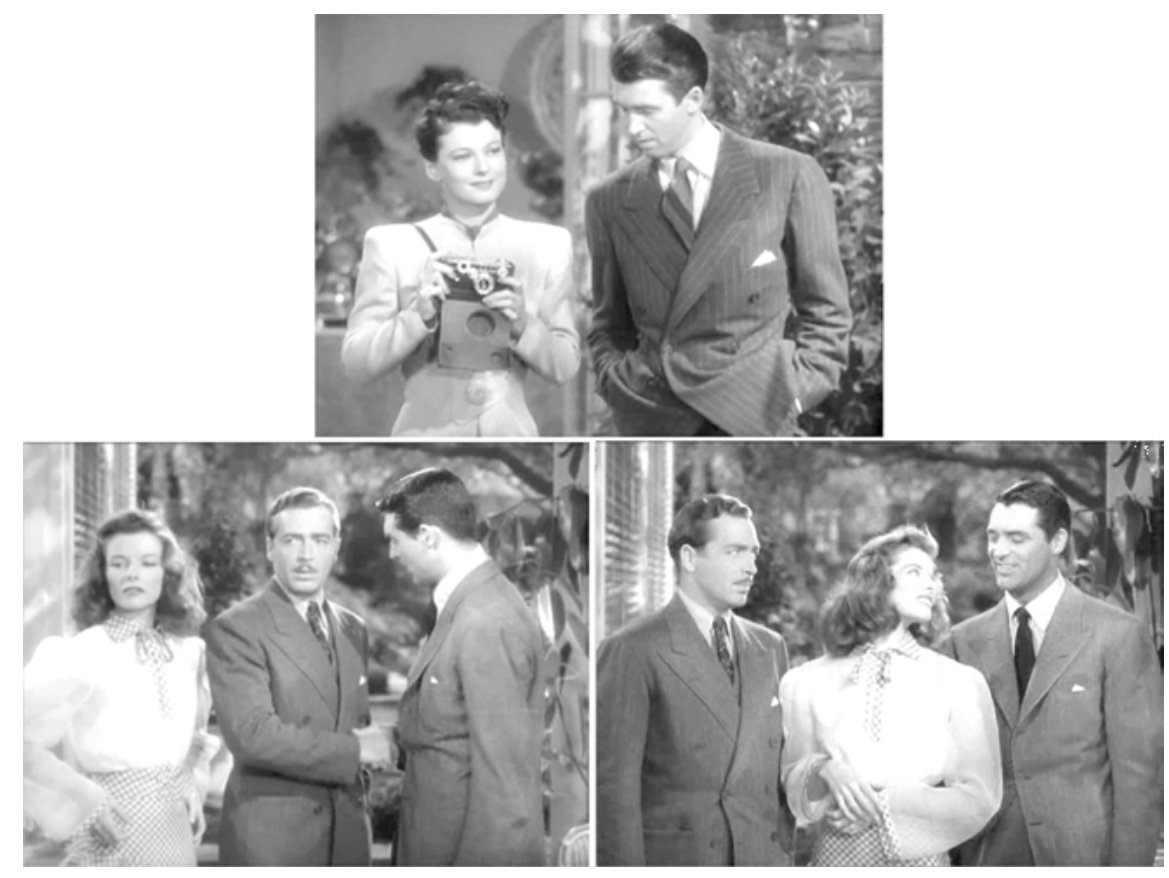

Abbildung 34: Fotografiergesichter in THE PHILADELPHIA STORY.

Die Mimiken zweier Grüppchen - je in der Frontalansicht - werden zueinander montiert. Das Reporter-Paar beobachtet observierend und hält immer wieder das Verhalten mit der Kamera fest. Kontrastiert wird dies vom Verhalten der Dreiergruppe mit Tracy, Dexter und George, wobei sich Bräutigam und Exmann die Hände schütteln. Der Fotoapparat klickt aus dem Off, die Dreiergruppe blickt zunächst offen und freundlich auf, doch dann kann man förmlich von den Gesichtern ablesen, dass ein Wandel einsetzt. Jeder von ihnen blickt neutral oder leicht nervös zur Seite, Grant dreht sich in seiner Körperhaltung leicht weg. Die Screwball Comedy hebt immer wieder diese Momente des gesellschaftlichen Verhaltens hervor, wie ein Körper sich zunächst offen verhält und wie er dann seinen Ausdruck verändert, gezielt lächelt, kontrolliert schaut und spricht.

Die Komödien zeichnen sich durch eben diese Wandlungen im Schauspiel aus, so dass subtile Gefühle, Einstellungen zwischen dem Wechsel übertriebener Gesten sichtbar werden. Diese Subtilität und Komplexität von Verhaltensformen betrifft nicht nur die eigentliche Schauspielkunst in den Komödien, z.B. so spielen, als würde jemand sich unwohl fühlen. Hinzukommt, dass dieses Sichtbarwerden, der Wechsel von Verhaltensweisen in einer einzigen Einstellung mit 
anderen Gesichtern zusammenkommt und für Zuschauerinnen ein Bild sozialer Verhaltenscodes darstellt.

Als Antwort auf eine abwertende oder spitze Bemerkung setzt Tracy das gesellschaftliche Lächeln auch ihrem Exmann entgegen. Beide zahnen sich an, die Künstlichkeit des Zeichens kann trotzallem nicht darüber hinwegtäuschen, dass ihre Körper sich immer wieder aufeinander ausrichten (Abb. 34). Es sind freilich Oberkörperansichten, doch die Mimiken sind die Spitzen, das Komprimierte im Schauspiel. Die Lust für die Zuschauer besteht darin, zu beobachten, wie in solchen Konstellationen von Gruppenmimiken Augenblicke von Subjektivität kurz aufblitzen, um dann wieder zu erlöschen, um überdeckt zu werden von der geselligen Miene oder dem falschen Lächeln. Man sieht Tracy spielen, wie sie zwischen ihrem Exmann, ihrem neuen Mann, der Familie und den Presseleuten ihr Verhalten einrichtet, als Inszenierung des perfekten Familienbilds. Das Zuschauergenießen stellt sich daraus her, $\mathrm{zu}$ beobachten, wie aus dem Stehgreif ein Theaterstück aufgeführt wird, wie es gelingt oder misslingt. War das Grimassenschneiden in den Anfängen der Filmkunst reiner Selbstzweck oder sinnliche Attraktion, so haben sich die Screwball Comedies dieses Element anverwandt und in eine reflexive Form transformiert. Die sozialen Codes und Emotionsregulationen im Zwischenmenschlichen, gesellschaftliche Etikette als Verhaltensnormierung, Tabus und Grenzen im Takt werden offenbar und über Prinzipien des Komischen reflektierbar. Außerdem bezieht sich das Grimassieren stets auf eine Absicht, ein Ziel, eine Maskerade. Für die Zuschauer bedeutet das, eine ,echte' Verbundenheit in den ,falschen' Mimiken zu erkennen, Anschauungsformen von Schamgefühle, Peinlichkeit zu erleben.

\section{Dynamische Qualitäten von Gesichtsbildern}

Man könnte sagen, dass der Wechsel vom gewöhnlichen zum posierenden Gesicht und zurück bereits eine bestimmte Zeitstruktur vorgibt, die an Fließen und Stocken, an ein sanftes Gleiten und die abrupte Unterbrechung gebunden ist. Die entlastende Heiterkeit, die anregende Vitalität und das Gefühl der Unbeschwertheit, das die Zuschauerfahrung beim Sehen der Komödien bestimmt, entstehen durch dynamische Qualitäten, z.B. durch die ausdrucksmäßige Leichtigkeit, Raschheit und die Vitalität der Kompositionen. Eine Szene aus MR. AND MRS. SMITH kann hierfür herangezogen werden. ${ }^{44}$ David

44 TC: 0:06:05-0:06:55. 
liegt ausgestreckt vor ihr, während Anne mit dem Rasiermesser sein Gesicht bearbeitet. Eine Halbtotale zeigt sie stehend, vertikal und ihn in einer Horizontalen. Dabei spricht sie davon, wie eine gute Ehe pragmatischerweise aufgebaut sein muss: „Respect for each other as persons, that's our big trick“ - „Mmh“ - „Man and woman alright, but person to person, that’s marriage too.“ - „Hm“. Während sie aus der Untersicht zu sehen ist, ist sein Gesicht - mit weißem Rasierschaum bedeckt - aus der extremen Aufsicht zu sehen. Er kann nicht sprechen, weil sie das Messer um den Mund herum ansetzt. „Mmh“ ist seine einzige mögliche Reaktion auf das von ihr Gesagte. Während sie spricht („Respect for each other as individuals, that's what counts. Always tell the truth, no matter what the consequences.") bittet sie ihn, damit sie ihn besser rasieren kann, darum, einen bestimmten Gesichtsausdruck anzunehmen. Sie posiert, macht es ihm vor, sie bläht eine Wange zeigend-hinweisend auf, dass sie sich kugelrund ausformt. Im Umschnitt nimmt er diese Pose an, dann sieht man ihre Hände flink an seinem Gesicht arbeiten. Ihre raschen Bewegungen, die Worte über das Vertrauen und den Respekt in einer Ehe werden kontrastiert durch seinen angespannten und passiven Gesichtsausdruck sowie durch das kratzende Schaben des Rasiermessers.

Zudem verbinden sich mehrere Dimensionen: Erstens erlebt man einen Kontrast zwischen dem ruhigen Sprechfluss und Davids punktuellen Zustimmungen. Zweitens bricht das posierende Gesicht, auch wenn es dem narrativen Fortgang dient, mit dem ruhigen Fluss, der bisher vorherrschend war (dem neutral blickenden, gewöhnlichen Gesicht). Drittens wird bildlich ein Ungleichgewicht durch extreme Kameraperspektiven (Aufsicht/Untersicht) sowie durch das Schauspiel inszeniert: Annes Omnipräsenz in Handeln, Sprechen und Aktion. Dadurch erlebt man eine starke Hierarchie. Man sieht einen völlig ausgelieferten Mann, der nichts sagen kann außer zuzustimmen und eine Frau, welche übergroß, von unten mit einem Rasiermesser in der Hand an seinem Hals hantiert. Der Dialog kontrastiert das Sichtbare, er handelt von Gleichgewicht und Gleichberechtigung (Abb. 35).

All diese Ebenen fließen ineinander, so dass sein Nicht-Antworten-Können als komisches, verstörendes Element in einem weichen, fließenden Kontinuum erscheint. Dies und der offensichtliche Widerspruch zwischen Gesagtem (Gleichheit) und Gesehenem (Hierarchie) erzeugt die Komik der Szene. Das Bild wird zu einem ironischen Kommentar auf den Dialog (man könnte es mit Cavells Worten beschreiben: "the acceptance of human relatedness, as the acceptance of repetition“ ${ }^{45}$ ). Nach und nach wandelt sich die Szene intimster Nähe 
und Alltäglichkeit, sie kippt in absolute Ausgeliefertheit und Ohnmacht, gegenüber Annes Rede und ihrem Handeln.

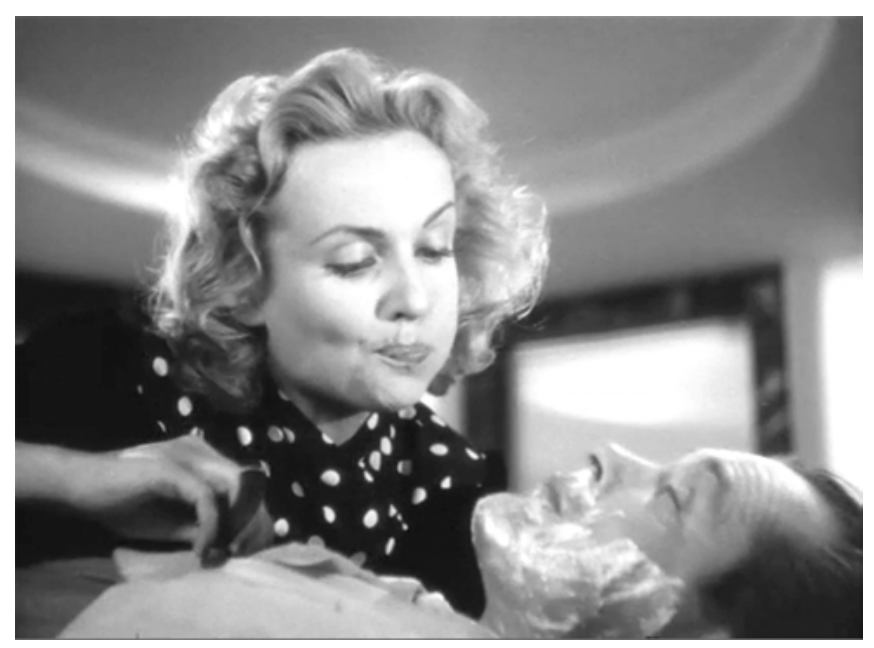

Abbildung 35: Zeigend-hinweisende Mimik in MR. AND MRS. SMITH.

Ein prominentes Muster der Zeitgestaltung der Komödie - betrachtet man es auf der Ebene von Gesichtsbildern - kann man als geschmeidige, fließende, viskosive Bewegungen beschreiben, die plötzlich durch Störungen, abrupte Wechsel unterbrochen werden. Es betrifft die Kommunikationsfunktion des Gesichtes in zweierlei Weise: das gewöhnliche Gesicht, das in gewisser Weise zum Sprechen, Reagieren und Kommunizieren verdammt ist und welches durch das posierende Gesicht unterbrochen wird, das versucht, aus dem starren Rahmen auszubrechen. Die Inszenierung zeigt eine Selbst-Behauptung, in der zwar das Individuelle behauptet wird, aber nie $\mathrm{zu}$ seinem Recht kommt. Immer ist es schon gerahmt, kontextualisiert, immer schon wird ein Gesicht von einem anderen überdeckt. Gerade aus diesem empfundenen Widerspruch entsteht das Komische. Man mag nun die Bewegungsbilder mit den Begriffen der Freude oder auch Überraschung, Spannung, Erwartung beschreiben. Entscheidend ist die Tempo- und Rhythmusgestaltung: Fließende Bewegungen in hoher Geschwindigkeit, die durch eruptive Elemente ins Stocken oder Pausieren geraten, können zwar als Zeitform der Überraschung sich ausprägen, verbinden sich aber auch mit anderen affektiven Modi.

Durch ihre Kommunikationsfunktion treten das gewöhnliche und das posierende Gesicht ihre eigenständige Ausdrucksdimension weitgehend an die 
Montage ab, ganz so, wie Hitchcock und Bonitzer es formulierten. Seine Wurzeln hat dieses Arrangement im Kuleschow-Effekt, der meist eher auf das im Bild Dargestellte reduziert wird (das Gesicht, die Suppe etc.). Was dabei aus dem Blick gerät ist, welche Rolle die Dynamik der Montage selbst spielt. Pudowkin erläutert, welchen großen Stellenwert gerade die zeitliche Gestaltung der Montagesequenz im beschriebenen Kuleschow-Experiment hatte:

Doch es geht nicht nur darum, Einstellungen in unterschiedlicher Reihenfolge zueinander in Beziehung zu setzen. Es muss auch noch die relative Dauer jeder Einstellung reguliert werden. Die Korrespondenz von Einstellungen unterschiedlicher Länge schafft - wie in der Musik die Kombination von Klangbildern unterschiedlicher Dauer - den Rhythmus des Films, und er wirkt auf den Zuschauer unterschiedlich. Kurze, schnelle Einstellungen erregen, lange beruhigen. Man muß die erforderliche Abfolge der Bilder und in ihrer Verknüpfung wiederum den notwendigen Rhythmus finden - darin besteht die entscheidende künstlerische Arbeit. Diese Kunst nennen wir Montage. ${ }^{46}$

Der Effekt des sich Zusammensetzens der Einstellungen hängt entscheidend von ihrer Länge ab, von Rhythmus und Tempo der Montagebewegung. Pudowkin betont die Zeitgestaltung als höchste Mittel der Wirksamkeit („Kurze, schnelle Einstellungen erregen, lange beruhigen“). Doch was in diesem Zusammenhang außerdem wichtig wird, ist die Art und Weise, wie Dargestelltes (Gesicht, Schauspiel) und Darstellungsform (Großaufnahme, Montage etc.) zusammenwirken und so z.B. durchaus lange Einstellungen etwa durch das Schauspiel dynamisiert werden können. Mit dieser Perspektive lässt sich die Herausforderung benennen, die schauspielerischen und bildlich-audiovisuellen Inszenierungsweisen als ein zeitliches Kompositum zusammenzudenken, wie ich es in den Kapiteln 3, 4 und 5 vorgeschlagen habe.

Im Folgenden werde ich Formen der Heiterkeit, die man als Zuschauerin in den Komödien erfährt, an einem Beispiel in den Blick nehmen; zweitens sind die Bildformen stark an die Art und Weise gebunden, wie das Schauspiel eine bestimmte Emotion ausdrückt oder karikiert; drittens sind Gesichtsbilder auch damit verbunden, was man als repräsentierte Darstellung von Gefühlen versteht; der Wunsch, die Intention oder Gemütslage einer fiktiven Figur.

46 Pudowkin 1983 (1929), S. 355. 


\subsection{Kontrastempfindungen, Zuschauergefühle, Emotionsdarstellung und repräsentierte Gefühle - THE AWFUL TRUTH}

Lag in den Analysen der letzten Kapitel der Fokus auf der Gefühlsmodellierung, so steht nun vor allem im Vordergrund, wie man eine Szene empfindet und versteht. In diesem Kapitel geht es darum, wie aus Bewegung und Gefühl ein Verstehensprozess evoziert wird. Die Bildtypen des gewöhnlichen und posierenden Gesichts spielen auch hier eine Rolle. Dabei rückt ins Zentrum, auf welche Weise Emotionsdarstellungen im Schauspiel mit dem Zuschauergefühl zusammenhängen bzw. ob man aus ihnen Rückschlüsse ziehen kann auf das, was innerhalb der Diegese als ,Figurengefühl' nachvollzogen wird.

Dabei gehe ich von einem Figurenbegriff aus, der nicht zuerst am Repräsentierten ansetzt, das heißt, der nicht von vorab ,gegebenen', existenten Narrationen und fiktiven Figuren ausgeht. Stattdessen frage ich danach, wie ein fiktives Imaginieren von Figuren auf basalster Ebene zustande kommt. ${ }^{47}$

\section{Mimische Argumente}

Das Antlitz verbindet sich mit anderen Gesichtern; diese werden zu einer visuellen Markierung, widersprechen sich, ergänzen oder unterbrechen einander. Eine Auseinandersetzung wird zwar verbal eingeführt, aber auf der Ebene von Gesichtern ausgetragen. Sie bekommen in der Screwball Comedy den Status von Argumenten. Die Montage stellt ganz verschiedene Ausdrücke auf eine Art zusammen, so dass sich daraus ein neuer Sinn herstellt. In THE AWFUL TRUTH geschieht dies anhand von drei Gesichtern im Wechsel.

Die Sequenz, die an der Türschwelle stattfindet, beginnt in Lucys (Irene Dunne) Apartment mit einem Gespräch über die Scheidung zwischen Lucy und ihrem Exmann Jerry (Cary Grant). ${ }^{48}$ Als Jerry sich verabschiedet und aus der Tür treten will, hört man die Stimme Dans (Ralph Bellamy) im Gang. Lucy schiebt die Tür soweit auf, dass Jerry hinter der Tür verschwindet (Abb. 36).

$47 \mathrm{Zu}$ einem komplexen narrativen Figurenbegriff siehe Jens Eder: Die Figur im Film. Grundlagen der Figurenanalyse. Marburg 2014; die folgenden Überlegungen haben das Ziel, sehr grundsätzlich das Verstehen einer narrativen Fiktion aus dem Wahrnehmungsprozess der Bewegungsbilder zu erklären. Siehe Kappelhoff und Greifenstein 2016.

48 TC: 0:44:48-0:48:10. 


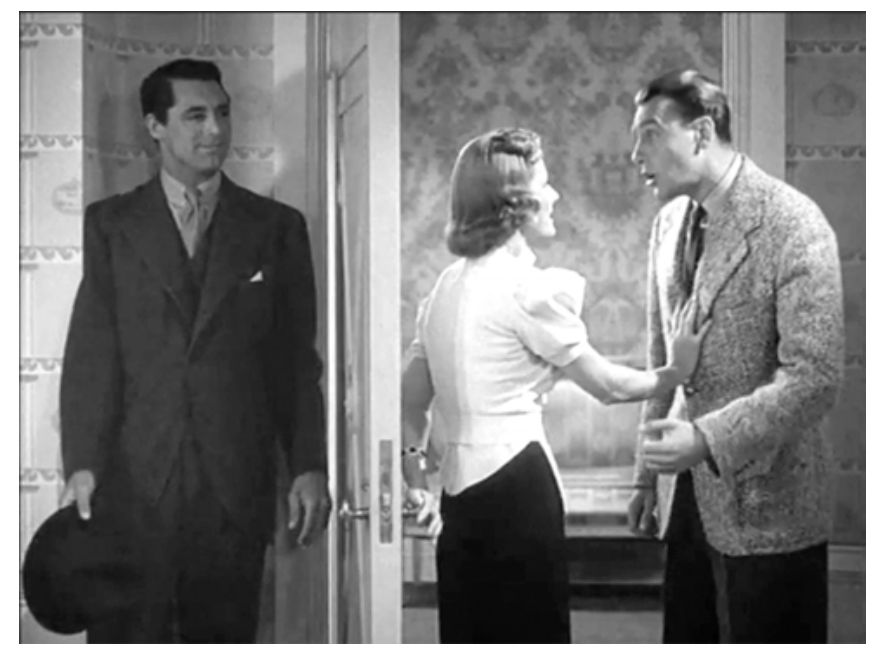

Abbildung 36: Szene an der Türschwelle - THE AWFUL TRUTH.

Man sieht ein geteiltes Bild, in dem links hinter der Tür Jerry steht und rechts vor geöffneter Tür Dan und Lucy miteinander sprechen. Im Folgenden wird diese Konstellation zum komischen Spiel zwischen Offenheit und Verstecktsein. Dan möchte einen Zwist mit Lucy in Ordnung bringen. Er trägt Lucy ein Liebesgedicht vor, sagt ihr, dass er ihretwegen nachts nicht schlafen könne und am Ende der Szene umarmt er Lucy nach einem Kuss auf die Wange überschwänglich, wirbelt sie umher und geht ab. Während dieser ,offiziellen' Unterhaltung gibt es parallel eine Handlung, welche von Jerry gesteuert ist. Von seinem Versteck aus konterkariert er immer wieder das Gespräch, so etwa indem er Lucy, während Dan ihr das Gedicht vorliest, mit einem Bleistift unter den Achseln kitzelt, wobei Dan es nicht sehen kann. Lucy lacht immer wieder und wehrt mit Stößen gegen die Tür Jerrys Störungen ab. Zudem klingelt zwischendurch das Telefon, ihr Gesangslehrer will sich ebenfalls mit ihr verabreden. Als Dan aus der Tür ist, sprechen Lucy und Jerry noch kurz miteinander, dann verlässt er ebenfalls die Wohnung.

Das komische und heitere Genießen wird in der Szene dadurch inszeniert, dass man einem offiziellen und einem versteckten Kommunizieren beiwohnt. Das Spiel um Lucy, ihre Mittlerposition zwischen einem Gespräch mit ihrem Verlobtem und einem heimlichen non-verbalen Austausch mit ihrem Exmann ist in mehrfacher Weise vitalisiert bzw. aufgeladen: Zum einen gibt es die Lust zu sehen, wie eine Art bühnenhaftes Geschehen erzeugt wird, wobei die Tür die Funktion des Theatervorhangs einnimmt und On-Stage und Off-Stage markiert. Jerry erscheint wie der Meister der verborgenen, soufflierenden Regie, er kitzelt Lucy rhythmisch 
immer zu einem bestimmten Zeitpunkt am Ende einer Zeile oder eines Reims, so dass ihr Lachen stets als Antwort auf Dans Worte erscheint (was dessen Liebeschwüre ins Lächerliche zieht). Lucy wird in kurzen Momenten zur Marionette.

Zum anderen erscheint das heimliche Kitzeln auch als ein leidenschaftliches Spiel zwischen Lucy und Jerry. Die verborgene Berührung und körperliche Vertrautheit, die man als Zuschauer über die Montage und nahe Einstellungen erlebt, entlädt sich erst durch Lucys Lachen. Dabei ist das körperliche Interagieren der beiden rhythmisch gestaltet: man sieht Jerrys Hand in der Großaufnahme; langsam und zart bewegt er den Bleistift in Richtung ihres Oberarms, und in der nächsten Einstellung sieht man Lucy von Nahem laut glucksen und lachen. Dann wieder sieht man ihre Bewegung, wie sie die Tür nach hinten drückt, was wiederum eine Großaufnahme von Jerry auslöst, die zeigt, wie er zunehmend in die Ecke gedrängt wird. Rhythmisch werden mehrere Nah- oder Großaufnahmen so aufeinander bezogen, dass sie sie wie einzelne Schläge oder Töne in der Musik wahrnehmbar werden.

Währenddessen erscheint Dans Sprechen als nebensächlich, man hört es aus dem Off; immer wieder wird in der Montage von Dan weggeschnitten, immer wieder verlagert sich der Fokus auf Jerrys Hand, auf ihren Oberarm, auf sein Gesicht und ihr Lachen. Die filmische Inszenierung deutet freilich nur an, doch die Art und Weise, wie das Kitzeln als Akt in der Großaufnahme ausgestellt wird, die sinnlich-belebte Weise des Schauspiels von Dunne und Grant sowie die Montage der Körperteile und Gesichter ergeben im Zusammenspiel das Bild von Flirt und Begehren.

Die Art und Weise, wie die Einstellungen zueinander gestellt sind, lassen sich auf der beschriebenen Ebene fassen. Doch das, was die Einstellungen verbindet, ist eine durchgehende kinematografische Bewegung. Sie ist der Teil, welcher die für den Zuschauer spürbaren Bewegungsqualitäten in das Erleben der Szene induziert und so das eigene Empfinden wieder auf das Leinwand-Geschehen bezieht.

\section{Die Pendelbewegung und das Gleichgewicht}

Mit dem Öffnen der Tür teilt sich zu Beginn der Szene der Raum bildkompositorisch auf, die Tür ist dabei das trennende Element. Die Zweiteilung des Bildes setzt sich in der Montage fort. Dabei sieht man zum einen Lucy und Dan in einer Zweiereinstellung, einander zugewandt, im Rücken Lucys die Tür. Zum anderen sieht man Jerry (hinter der Tür) in einer Großaufnahme zwischengeschnitten. Dabei formt sich eine Zeitlichkeit aus, in der man stets eine längere Einstellung hat (Lucy und Dan, nah, Abb. 38), welche von einer kurzen, abrupten Einstellung unterbrochen wird (Jerrys Gesicht, groß) (Abb. 37). Ausgelöst 


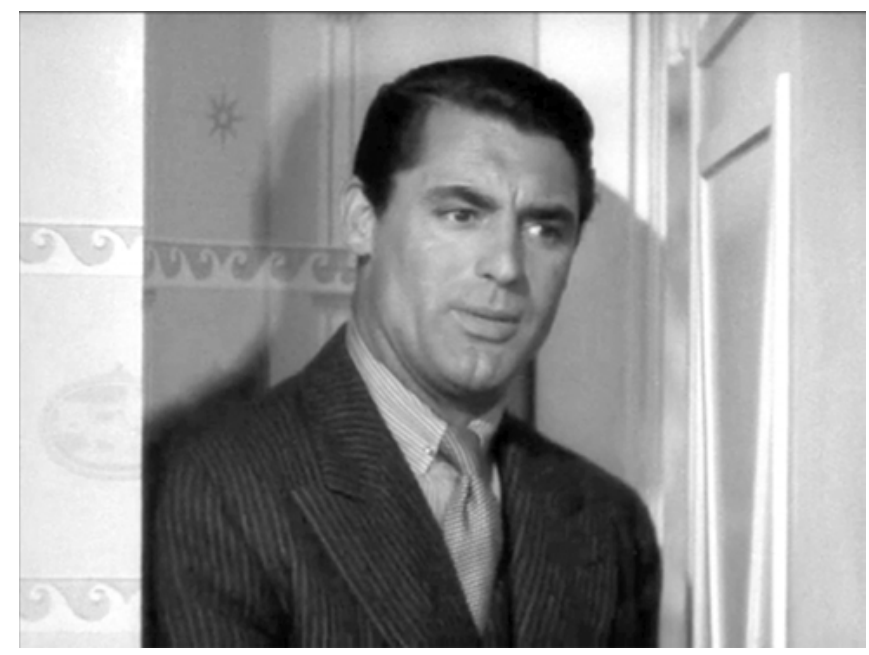

Abbildung 37: Mimische Bewertung und Kommentierung in THE AWFUL TRUTH.

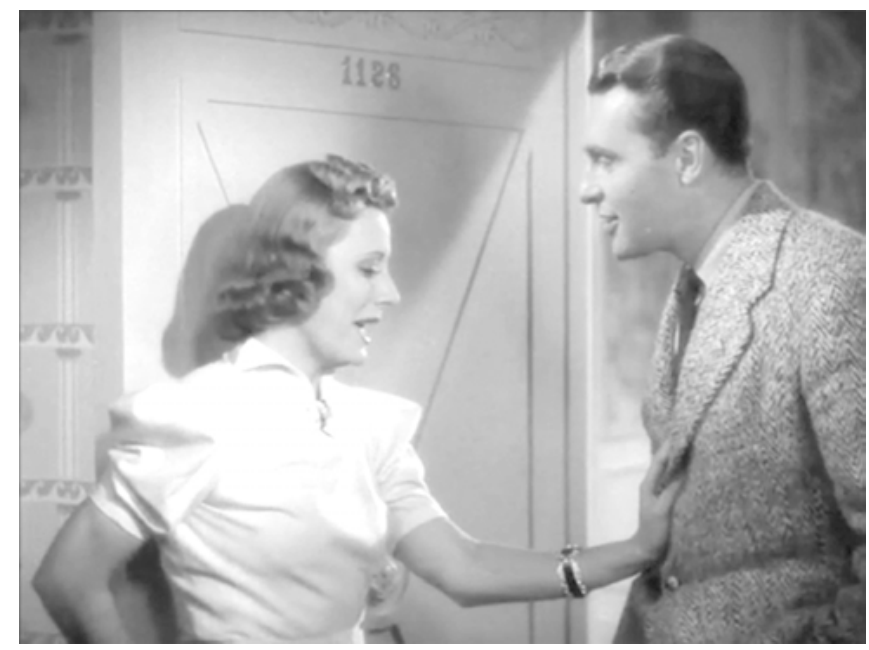

Abbildung 38: Das offizielle Sprechen in THE AWFUL TRUTH.

wird der Einstellungswechsel durch die Schauspielbewegungen Lucys, welche die Tür stark nach hinten drückt, worauf man als Zuschauerin Jerrys verdutztes, erstauntes oder schelmisches Gesicht in der Großaufnahme sieht.

Es etabliert sich ein Rhythmus aus Montage, Schauspiel und Rede, der zwischen langgezogenen, gedehnten und kurzen, abrupten Elementen wechselt. Dieser Rhythmus steigert seine Intensität, indem er in seinem weiteren Verlauf 
sich verändert zu einem lang - kurz, kurz, kurz, wobei die ,Schläge‘ aus folgenden Elementen bestehen: Lang ist die langsame, kontinuierliche Rede Dans, die ihre Entsprechung in der längeren Einstellung von Lucy und Dan hat. Kurz ist die Großaufnahme des Gesicht Grants, kurz ist die Hand in einer Großaufnahme, die den Bleistift hält und kurz ist das abrupte, laute Glucksen und Lachen Lucys. Dieser Rhythmus wird einige Male wiederholt, bevor er sich durch das Telefonklingeln und dem damit verbundenen Einstellungswechsel auflöst. Darauf folgt eine distanziertere Einstellung, in der Dan Lucy hochhebt und sie herumschwingt, eine Art Pendelbewegung ausführend, und dann aus dem Bild abgeht. Der Wechsel der Einstellungen ist eine Art bildliche Waage, die zu einem Pendeln ${ }^{49}$ wird; für den Zuschauer beschreibt der Montagerhythmus im Wechsel eine Schwenk-, Wipp- und Wiegebewegung. Diese Bewegung wird durch eine Verknüpfung von Montage, Schauspiel und Bildkomposition hergestellt. Ihr Bildraum, der nicht dem dargestellten Raum entspricht, eine Fiktion dessen aber erzeugt, hat an der Tür (und bei Lucy) seine Mitte und schwenkt durch die Einstellungswechsel mal zur einen und dann zur anderen Seite aus. Die Bewegungsfiguration wird an einer Stelle innerhalb des Bildfelds gebündelt, als Dan Lucy hochhebt und herumschwingt. Das Empfinden lässt sich dabei als sich wiederholendes Herstellen von Gleichgewicht beschreiben, das jedoch ständig ins Wanken gerät, unregelmäßig wird und überzukippen droht.

Ein erneuter Einstellungswechsel zwischen Lucys Gesicht und dem Gesangslehrer, der sich an einem anderen Ort befindet (von etwas weiter weg zu sehen), variiert das Muster im zweiten Teil der Szene.

Die Bildkomposition setzt nun Jerry in die Mitte, den Ausschlag des Pendels beschreiben Lucys Schauspielbewegungen im Bild. (Man sieht Lucy rechts stehend, das Telefon mit dem Anrufer links. Jerry weist sie mit einer Zeigebewegung auf den Telefonhörer hin, dann wechselt sie die Seiten. Nach dem Telefonat, wechselt sie wieder die Seite). Am Ende der Szene stehen Lucy und Jerry einander vor der geschlossenen Tür gegenüber, sie sind symmetrisch im Bild angeordnet - das Pendel ist zum Stillstand gekommen - dann geht Jerry aus der Tür. Die filmische Ausdrucksbewegung lässt sich als anfänglich ruhige Qualität des Gleichgewichts beschreiben (artikuliert durch Montage, Bildkomposition und Schauspiel), welches in starke, unregelmäßige Schwingung gleich einem aus dem Lot geratenen Pendel - versetzt wird und in einer kleineren Pendelbewegung schließlich zum Stillstand kommt (überwiegend durch

49 Man könnte die Bewegung auch mit dem Bild eines Kugelstoßpendels beschreiben, wobei alle Kugeln an Schnüren aufgehängt sind und die eine Kugel die nächste und diese dann wieder die nächste anstößt. Für diesen Vergleich bin ich Matthias Grotkopp dankbar, der Gedanke stammt von ihm. 
Kadrierung und Bildkomposition). Das Gefühl, das zu dieser Bewegung kongruent ist, ist eine Ruhe, die in Aufregung versetzt wird und sich als freudiges Genießen angesichts einer Vitalität (Bewegungsspiel) entfaltet, bis sie wieder in Ruhe übergeht. Im Folgenden möchte ich erörtern, wie das Schauspiel mit diesem Vitalitätsempfinden zusammenhängt. Dabei betrachte ich, wie das Schauspiel in die filmische Bewegung eingeht, wie sich körperliche in filmische Expressivität einbettet. Die Gesichter von Dan, Lucy und Jerry sind Elemente der Ausdrucksbewegung, sie lassen sich als Bewegungsfiguration, aber auch als einzelne Elemente beschreiben.

\section{Emotionsdarstellung im Schauspiel}

Das Schauspiel und seine Emotionsdarstellungen, die in die filmische Ausdrucksbewegung eingebettet sind, haben eine eigene Funktion innerhalb der Szene. Zu Beginn sind die mimischen Darbietungen von Jerry und Lucy relativ neutral. Als Dan in die Tür tritt und sich der Bildraum aufteilt, beginnt das Spiel der sich widersprechenden Mimiken. Die Gesichter laufen zunächst einfach nebeneinander her; nach kurzer Zeit beginnen sie jedoch in unterschiedliche Richtungen $\mathrm{zu}$ divergieren. Immer wieder sieht man den fröhlich-heiteren Austausch von Dan und Lucy in der Zweiereinstellung. Kontrastiv dazu wird Jerrys Gesicht als die friedvolle Konversation störende Mimik (Insert einer Großaufnahme) eingeschoben; sein Gesicht ist mal verdutzt, mal unbehaglich, mal amüsiert, mal genervt (er lauscht den Liebesworten Dans) oder schelmisch-lustvoll (er kitzelt Lucy).

Der Wechsel aus langen und kurzen Einstellungen (wie oben ausgeführt) setzt sich fort. Darin sieht man den Wechsel aus Jerrys und Lucys Mimiken als harmonisches Interagieren. Die Montage verschaltet die Körperbewegung miteinander, so beginnen sich die mimischen Bewegungen von Jerry und Lucy zu entsprechen: z.B. hat sein belustigter Gesichtsausdruck aufgrund seiner List, sie zu kitzeln, eine Resonanz in Lucys Versuch, das Lachen zu unterdrücken. Doch die Entsprechungen der mimischen Darbietungen werden allein durch die Montage als ähnlich, kongruent oder aufeinander bezogen realisiert.

Zudem spielt die Kadrierung eine wichtige Rolle für das Wahrnehmen des Schauspiels: In der Nah- oder Großaufnahme sieht man Jerrys feinmotorische Bewegungen. Feine, mimische Bewegungen oder leichte Handbewegungen wechseln sich ab mit dem posierenden Gesicht. Doch letzteres ist in einer Weise ausgestellt, dass es elegant, reizvoll und zart erscheint. Selbst die kleinste, feinste Bewegung, in der er sie noch nicht einmal direkt berührt (Bleistift), hat einen großen Effekt: Lucys Körper spannt sich an, reagiert auf die Kitzelbewegung und entlädt sich eruptiv als Lachen. Dan ist im Gegensatz hierzu inszeniert: Man sieht 
ihn von weiter weg, stets nur zusammen mit Lucy, seine groben Körperbewegungen versteifen sich in der fröhlichen Haltung, er hält Lucys Hände starr und angespannt fest, dann umarmt er sie fixierend, hebt sie fest hoch, lässt sie nicht mehr los und schwingt sie heftig hin und her. Seine Körperbewegung wirken schwer und grob. Im Anschluss, als Dan gegangen ist, sieht man Lucy mit einer peinlich, berührten Miene, Jerry mal lächelnd, dann abwartend bzw. neutral.

Die mimischen Bilder zeigen ein Emotionsschauspiel, das nie nur auf sich, auf das einzelne Gesicht verweist. Immer schon regt sich etwas in Bezug auf ein anderes. Es ist die Montagebewegung, welche auf komplexe Weise die einzelnen Regungen mit den anderen Gesichtern verschaltet. So kommentiert Jerrys kritisches Gesicht immer wieder das Geschehen zwischen Lucy und Dan: Die Großaufnahme Grants schreibt in ihrer Kommunikationsfunktion des posierenden Gesichts stets die mimischen Regungen den folgenden oder vorausgehenden Einstellungen ein. Da Grants Gesicht so nah und wiederholt zu sehen ist, überdecken seine Bewegungen alle folgenden Einstellungen: Man sieht nicht Dans liebevollen Versuch eines Liebesgeständnis, sondern man sieht diesen Akt als Lächerlichkeit, die jedoch nicht der Handlung selbst, sondern dem genervten Blick Grants entspringt. Grants Gesicht, das hier prominent wird, wandelt sich und mit seiner Mimik verändern sich auch die Bewertungen gegenüber den Handlungen, die man sieht, gegenüber den Worten, die man hört.

Cary Grants Gesicht erfährt innerhalb der Montagesequenz eine Zentrierung, Betonung und Akzentuierung, es tut sich hervor, wird dominant. Es ist dieser Sinn gemeint, wenn Ejchenbaum vom Akzent durch die Großaufnahme spricht:

Wenn man im Allgemeinen unter ,Satz‘ eine tatsächliche, als Segment (sprachliches, musikalisches usw.) wahrgenommene Gliederung sich bewegenden Materials versteht, dann kann man ,Satz' definieren als eine Konstellation von Elementen, die sich um einen akzentualen Kern gruppieren. Zum Beispiel wird der musikalische Satz gebildet durch eine Gruppierung der Töne um einen rhythmisch-melodischen oder harmonischen Akzent, hinsichtlich dessen die vorhergehende Bewegung eine Vorbereitung ist. Eine analoge Rolle spielt im Film die Gruppierung verschiedener Aufnahmedistanzen und Aufnahmewinkel..$^{50}$

Die akzentualen Satzglieder werden durch Vordergrundeinstellungen und Großaufnahmen geschaffen, die eine Art Subjekt und Prädikat des Filmsatzes sind. Die Bewegung der Aufnahmedistanzen (von der Totale zum Vordergrund und danach zur Großaufnahme oder auch in anderer Reihenfolge), in deren Zentrum die Großaufnahme als grundlegender stilistischer Akzent steht, ist das fundamentale Konstruktionsgesetz des Filmsatzes. ${ }^{51}$

50 Boris M. Ejchenbaum: Probleme der Filmstilistik. (1927) In: Wolfgang Beilenhoff (Hg.): Poetika Kino. Theorie und Praxis des Films im russischen Formalismus. Frankfurt a. M. 2005, S. 20-56, hier: S. 42.

51 Boris M. Ejchenbaum 2005 (1927), S. 43. 
Der Filmsatz ist für Ejchenbaum weniger an eine Grammatik gebunden als an eine Auffassung sich „bewegenden Materials“, welches eine Struktur herstellt, die zu einer Bedeutung wird, da es sich gliedert bzw. segmentiert. Ejchenbaums Zitat vom Gesicht als Akzent ist hier relevant, weil er die Einstellungswechsel im Film rhythmisch-musikalisch auffasst. Damit stellt sich eben die Form einer Akzentuierung her, die auf den Wahrnehmungsakt des Zuschauers abzielt.

In diesem Sinnzusammenhang beschreiben die kontrastiven Gesichter in der Szene bildliche Intensitäten. Durch die Inszenierung der Pendelbewegung erlebt man auch die Teile dieses Pendels: einen Pol, der schnell, leicht, nah zu sehen, feinmotorisch und im Emotionsausdruck äußerst wechselhaft ist. Diesem Pol entspricht das Schauspiel Grants sowie die kurzen Einstellungen der Montage. Der andere Pol ist als langsam, schwer, distanziert, grobmotorisch und im Emotionsausdruck gleichbleibend wahrnehmbar. Er entspricht dem Schauspiel Bellamys sowie den langen Einstellungen in der Montage. Der Rhythmus der Einstellungswechsel ist hingegen an den Schauspielbewegungen Dunnes (Lucy) ausgerichtet, sie hält beide Pole zusammen, ihre Bewegungen scheinen eine Montagebewegung auszulösen.

Ähnlich wie in den Kapiteln zu Stimme und Gestik ist hier anhand des mimischen Schauspiels festzustellen, dass die Emotionsregister der Schauspieler sich fluide wandeln und selten als Ausdruck einer Individualität sichtbar werden. Stets kommuniziert das einzelne Gesicht, setzt sich zusammen mit anderen Gesichtern. Durch die starke Funktionalität der einzelnen Einstellungen in der Montage wird mehr das Gemeinschaftliche in den Vordergrund gerückt: Es ist eine Lust, dabei zuzuschauen, wie Jerry die Unterhaltung stört, wie das heimliche/eigentliche Paar (Jerry und Lucy) nonverbal und sinnlich miteinander kommuniziert und wie Lucy alles in der Schwebe hält. Das Schauspiel des Einzelnen wird durch die kinematographische Bewegung (und durch das Zuschauerempfinden) nichtig gemacht. Man sieht es, doch es wird nicht primär. So nimmt man in Lucys Gesicht die anfängliche Kühle, ihr gespieltes Verhalten, ihr Lachen, Sich-Amüsieren und die Peinlichkeit wahr, doch dieses Regungsverhalten wird zwar sichtbar abgeschritten, aber es ist kaum affektiv nachvollziehbar, da es durch das Zuschauergefühl einer Heiterkeit und Vitalität, das von der Ausdrucksbewegung geformt wird, überlagert wird.

\section{Repräsentierte Figurengefühle}

Standen in der Analyse bisher die filmische Ausdrucksbewegung sowie das Emotionsregister des Schauspiels als damit aufs Engste verwoben, im Mittelpunkt, so rekonstruiere ich im Folgenden das Fiktivwerden von Figuren und 
repräsentierten Gefühlen. Dabei gehe ich nicht von bereits bestehenden narrativen Figuren aus, vielmehr stellt sich die Frage, wie die Fiktion einer narrativen Figur überhaupt als solche zustande kommt, wie sich in der Filmerfahrung nach und nach eine Figur herausbildet.

Mit diesen Überlegungen schließe ich an Hermann Kappelhoff an, der aufgezeigt, auf welche Weise er das Zuschauerempfinden als Ausgangspunkt für ein fiktives ,Figurengefühl' betrachtet. So schreibt er in Bezug auf Lessings Mitleidsbegriff, aber durchaus in verallgemeinerndem Sinn: „Das sympathische Nachempfinden der Gefühlslage der Figur ist lediglich das Movens eines Selbstempfindens, das dem Zuschauer den Raum seiner eigenen Innerlichkeit eröffnet. “52 Den Schauspielakt fasst Kappelhoff im Kontext sentimentalen Empfindens in der Filmerfahrung gerade nicht als etwas auf, das vom audiovisuellen Bild abzulösen wäre. Aus dieser Perspektive, die eine Verwobenheit von Zuschauerleib und kinematografischer Bewegung meint, ist die „Gefühlslage“ der Figur etwas, das sich erst auf dem Grund des Selbsterlebens beim Zuschauer herstellt. Das eigene Empfinden richtet sich auf eine Schauspielbewegung, auf ein bestimmtes Teilelement, auf eine im Bild wahrgenommen Figürlichkeit aus, wird aber eigentlich durch das gesamte kinematografische Bild modelliert. Aus dieser Perspektive lassen sich das Gesicht des Schauspielers und der Affektausdruck keineswegs von der kinematographischen Gestaltung und seiner jeweiligen Bildform ablösen. Vielmehr perspektiviert die Kamera und auch die Montage das mimische Geschehen auf sehr spezielle Weise, verbindet Dargestelltes mit dem Darstellungsakt, Wahrgenommenes (das Gesicht) mit dem Wahrnehmungsakt kinematografischen Sehens und Hörens (wie man das Gesicht sieht). ${ }^{53}$

Und so gibt es Gesichter im Film, deren Gemütsregung nicht von der Kamera aufgegriffen wird. In Anlehnung an Lessings theatertheoretische Thesen zum Mitleid erörtert Kappelhoff im Zusammenhang mit dem sentimentalen Genießen die Unterscheidung von ,Affekten' und ,mitgeteilten Affekten'. Erstere sprechen den Zuschauer direkt an, sie werden durch die Inszenierung, die Bühne, die Gegenstände, das Licht und das Schauspiel modelliert. Die ,mitgeteilten Affekte' sind hingegen vom Schauspiel ausagierte Ausdrücke, die für den Zuschauer erkannt, aber gefühlsmäßig nicht nachvollzogen werden. ${ }^{54}$

Man kann im ersten Fall davon sprechen, dass es sich um ein Gefühl handelt, welches der Zuschauer selbst realisiert und gleichzeitig einer fiktiven Figur zuschreibt. Das Schauspiel ist in diesem Fall so, dass es kongruent zum

52 Kappelhoff 2004a, S. 81.

53 Sobchack 1992.

54 Kappelhoff 2004a, S. 80. 
eigenen Erleben wird. Im zweiten Fall hingegen zeigt das Schauspiel eine bestimmte Affektivität auf, diese überträgt sich jedoch nicht. Eine Kluft entsteht: Das durch Prozesse des Fiktionalisierens entstandene ,Figurengefühl' weicht vom eigenen Empfinden einer Szene ab und wird daher auch nur erkannt, aber nicht nachvollzogen.

Auch die Komödien operieren häufig auf der Basis dieser Einteilung. Das Besondere ist dabei, dass es beides zu geben scheint. So mag es sein, dass man höchst amüsiert ist, sich erfreut und gleichzeitig Gesichter von Peinlichkeit und Schamgefühl sieht. Entscheidend ist hier, die Figurengefühle nicht bereits als existente Entitäten zu betrachten, da sie rein fiktive Konstruktionen bzw. Vorstellungen sind. Man kann vielmehr sagen: Das Zuschauergefühl ist im komödischen Modus ein aus Widersprüchen bestehendes Empfinden, in dem die eigene Affizierung mit dem Akt des Erkennens, Abgleichens und Vorstellens (hervortretender Emotionsdarstellungen) kontrastiert wird.

So lässt sich auch die obere Sequenz unter diesem Gesichtspunkt betrachten. Die Figuren agieren, wir erleben bestimmte Affektausdrücke im Schauspiel - z.B. die Peinlichkeit in Dunnes Gesicht, Schadenfreude bei Grant und Fröhlichkeit bei Bellamy - doch die affektive Modulation besteht im raschen Wechsel; die Gesichter zeigen etwas, doch da springt die Montage wieder zu einer anderen Mimik. Die mimischen Affektausdrücke sind meist nur noch mitgeteilter Natur, während die Montagebewegung eine einheitliche Pendelbewegung beschreibt, welche ein Zuschauerempfinden des Gleichgewichts und des Ausdem-Gleichgewicht-Kommens anordnet.

Doch wie kommt man nun zum Verstehen bzw. zur Konstruktion, zur Fiktionalisierung eines Figurengefühls? In der Szene herrschen zwei Bildfelder: das offizielle Sprechen vor offener Tür und das Lauschen, Beobachten und die versteckte Kommunikation Lucys mit dem Exmann Jerry hinter der Tür. Die Verbindung und Trennung beider Bereiche wird durch Schauspielbewegungen Lucys sowie durch die Montage hergestellt.

Erst durch sichtbare mimische und gestische match-cuts sowie Kongruenzen auf der Ebene des Tons konstituiert sich der Bildraum als ein narrativer Raum. Man hört die Worte Dans, wie er ein Gedicht aufsagt und sieht parallel dazu Jerry, wie er die Augen verdreht. Dan hingegen macht keine Bewegungen, welche sich mit denen im Bildbereich hinter der Tür verbinden würden. Sein Gesicht, seine Worte und Gesten sind allein auf Lucy ausgerichtet. Es ist diese sehr basale Ebene, die uns verstehen lässt, dass Dan nichts von Jerrys Anwesenheit ahnt. Alles Verstehen gründet darauf, was man sieht und hört: Lucy steht zwischen beiden Männern und kommuniziert mit beiden; Jerry und Lucy haben eine Verbindung (durch die Montage), die Dan nicht sieht. Dans Verhalten hingegen wird ständig von Jerry mimisch kommentiert. 
Doch nicht allein diese Ebene ist entscheidend. Erst über die Zeit der Szene entfaltet sich mit der Bewegungsfiguration eine Figurierung von Dan, von Jerry, von Lucy entsprechend der Ausdrucksbewegung: Die Montage erzeugt eine Pendelbewegung - die Lust am Balancieren (aus dem Gleichgewicht geraten und ins Gleichgewicht kommen), wobei die einzelnen Figuren als Teile der Montage wahrnehmbar werden (Abb. 39).

Kadrierung und Schauspiel greifen so stark ineinander, so dass jedem Schauspielstil ein bestimmter Inszenierungsstil bzw. ein Element der Montage $\mathrm{zu}$ entsprechen scheint; das feine, motorische Spiel Jerrys wird mit kurzen, nahen Einstellungen besetzt etc.; Dans grobe Motorik verbindet sich mit einer distanzierteren Kamera und längeren Einstellungen; Lucy bewegt sich und ihre Bewegungen lösen die Einstellungswechsel aus. Dadurch wird ein Teil des Schauspiels auf die Wahrnehmungsebene des Zuschauers transponiert und umgekehrt: ein bestimmtes Sehen wird mit einer bestimmten Körperlichkeit ,konnotiert‘. Durch das Interagieren aller Elemente untereinander in der Montage wird eine Konstellation erzeugt: Man kann sagen, dass die gesamte Bewegung die Beziehungsrelation versinnlicht (Gleichgewichts- oder Pendelbewegung), welche vom Zuschauer als ein Gefühl realisiert wird. Innerhalb der Montage werden nun die einzelnen Elemente selbst in ihren Funktionen zu den Figuren.

So kann man sagen, dass aus der Ausdrucksbewegung (als Bewegungsfigur) eine konstruktive und perzeptiv motivierte Metapher ${ }^{55}$ entsteht, welche die narrative Figurenkonstellation ästhetisch erzeugt: Das Beziehungsgefüge als eine aus dem Gleichgewicht geratende Pendelbewegung, in die drei Positionen eingebettet sind. Den drei Positionen entsprechen die drei Figuren, ein anstoßendes Element (Jerry), ein reagierendes und rückstoßendes Element (Lucy) und ein bremsendes Element (Dan). Dabei finden Entsprechungen statt, in denen die einzelnen Elemente eine Verbindung von Schauspiel- und Montagebewegung beschreiben: Die Figur Dan ist das Ergebnis einer Komposition, in der auf der Ebene der Wahrnehmung sein langes, langsames Sprechen der Kadrierung, dass man ihn immer nur in längeren Einstellungen sieht, entspricht. Die Figur Jerry entsteht aus dem wechselhaften Emotionsgebaren Grants, das mit den kurzen, abrupten und wechselhaften Einstellungen in Einklang ist. Die Figur Lucy entsteht aus dem wechselhaften Changieren im Schauspiel, das der wechselhaften Montagebewegung als Ganzes - der Pendelbewegung -

55 Eine Cinematic Metaphor. Vgl. Müller und Kappelhoff 2018; Schmitt, Greifenstein und Kappelhoff 2014. 


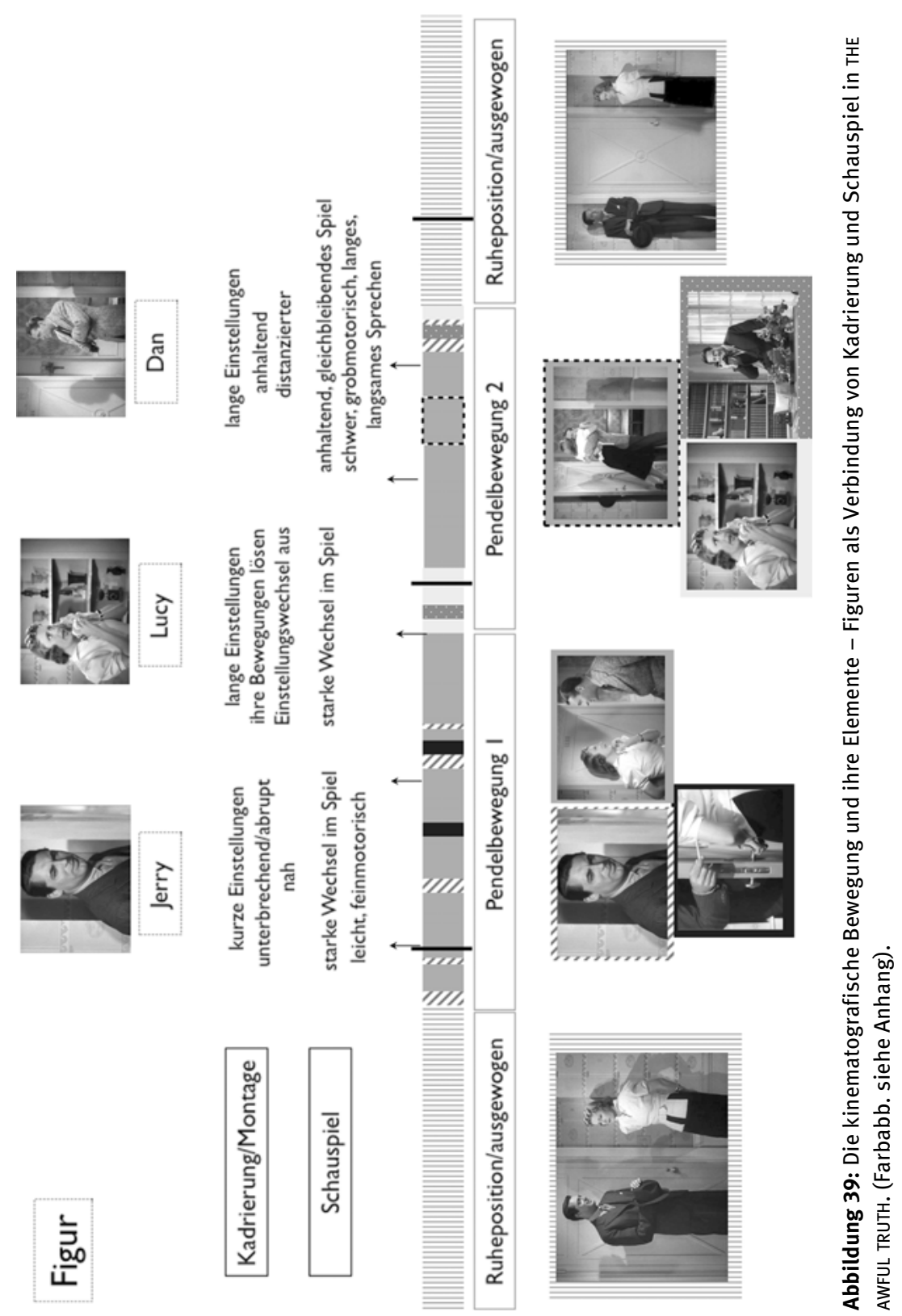


entspricht. Das, was als Entsprechungen aufeinander bezogen wird, entsteht durch sich verbindende Bewegungs- oder Ausdrucksqualitäten. Die Figuren sind demnach wiederkehrende Teile und Funktionen der gesamten Bewegung, die man sieht und erlebt als ein ungeteiltes Gefühl von Vitalität, Heiterkeit aber auch Peinlichkeit und als ein sich ausdifferenzierendes Verstehen, dreier Figuren, die jedoch immer schon an ihr Beziehungsgeflecht gebunden sind und nie in ihrer Individualität betont werden.

Die Figurengefühle sind daher auf dieser Ebene angesiedelt, sie sind das, was man durch die gesamte Montagebewegung versteht, bezogen auf einen Teil davon, den Ausdruck eines der Schauspieler. Das Aus-demGleichgewicht-Geraten und zum Gleichgewicht-Finden der Szene modelliert das Zuschauergefühl. Ein Element der Montage ist etwa ein Gesicht, das wechselhaft ist (Grant: kommentierend, amüsiert, schadenfroh), welches innerhalb der Inszenierung (nah, kurz, rasch) die Aktion des Pendelns, Schaukelns immer wieder anregt. Bremsend hingegen ist ein zweites Gesicht (Bellamy: gleichbleibend fröhlich) innerhalb einer immobileren Inszenierung (distanzierter, lange Einstellungen). Sie sind reine Konstellationen der Gesamtpendelbewegung, welche die unbehagliche Zwischenposition Lucys beschreibt.

Die Szene entwirft in plötzlicher Eile eine Bühne, Dunne wird zur Schauspielerin und zur Marionette zugleich, sie verbirgt nicht nur einen Teil der Szene, sondern gebärdet sich auch übertrieben Dan gegenüber. Der Reiz für uns $\mathrm{Zu}$ schauer besteht darin, dass die Entblößung für uns eine ständige Möglichkeit ist, die man nicht erhofft, aber die doch das Verbotene und Intime eines geteilten Geheimnisses zwischen dem Paar ausmacht.

Der Reiz des Versteckspiels, so könnte man sagen, basiert auf dem Oszillieren zwischen sichtbarem Überblick für uns Zuschauer und vorgestelltem, begrenztem Blick, der durch die Montage vorgegeben wird und den man den Figuren und deren Sichten zuschreibt: Dan sieht nur Lucy; der Zuschauer sieht alles; Lucy und Jerry sehen ebenfalls begrenzt; Jerry greift in den anderen Raum hinein, indem er Lucy mit einem Stift kitzelt oder anderweitig ärgert. Dadurch ist es weniger zutreffend zu sagen, dass wir es genießen, mehr zu wissen als eine Figur, sondern, dass wir uns gleichsam wie ein Regisseur fühlen: den Überblick über die Inszenierung zu haben und dabei zuzugucken, wie das Spiel für eine der Figuren (Dan) zu einer Illusion wird. Das zu Verbergende wird an die Mitsicht der Zuschauerin geknüpft und so als Teilhabe an der inszenierten Paarintimität imaginiert.

Die Screwball Comedies sind für die Frage nach diesen affektiven Inkongruenzen beispielhaft. Sie adressieren Zuschauergefühle, doch sie zeigen oftmals auch ein davon sehr deutlich unterscheidbares Verstehen dargestellter 
Emotionen. Susanne Langer schreibt, dass Komödien generell, auch im Theater, diese Paradoxität verhandeln: „Die Erscheinung des Lachens im Theater beleuchtet scharf die ganze Frage der Unterscheidung zwischen symbolisch dargestellter Gefühlsbewegung und unmittelbar hervorgerufener Gefühlsbewegung“. ${ }^{56}$ Was Susanne Langer beschreibt und schon vorher mit den „mitgeteilten Affekten“ angesprochen wurde, trifft in hohem Maße auf die Screwball Comedies zu: Man sieht Gesichter der Wut, der Verzweiflung, doch der Gefühlszustand der dargestellten Figur ist zwar erkennbar, wird aber als transitorisch oder nebensächlich behandelt. Was uns berührt, sind nicht die individuellen Gesichter, sondern die Gesichter als kontrastiver Ausdruck (hervorgerufen durch die Montage).

Mit der Metapher lässt sich auf basalster Ebene der Verstehensprozess rekonstruieren, der aus wahrnehmbaren Bewegungsfigurationen z.B. die Konstruktion einer narrativen Figur entwickelt. In der Frage nach den Figurengefühlen, was sie sind und wie sie sich konstituieren, kann man den Unterschied zu den Schauspielformen, die ein bestimmtes Emotionsrepertoire aufweisen, benennen. Ist der Emotionsausdruck in langen Einstellungen sichtbar, dann bekommt der Schauspielkörper selbst einen größeren Stellenwert im Gefüge und folglich wird auch das von ihm gespielte Gefühl stärker warhnehmbar. Ist der Emotionsausdruck im Schauspiel jedoch nur in seiner Momenthaftigkeit zu erleben, da er ein minimales Element einer höchst elaborierten Montage ist, so gehe ich davon aus, dass die Figurengefühle nicht einfach mit dem Ausdruck der Schauspieler gleichzusetzen sind. Vielmehr ist das, was man selbst als Zuschauer in der Szene affektiv erfährt, Teil eines Prozesses, indem man die eigene Empfindung aufs Schauspiel einer im Bild sichtbaren menschlichen Figur rückbezieht und entsprechend der Kongruenz oder dem Auseinanderfallen mit dem schauspielerischen Ausdruck als Bedeutung konstruiert.

Auf dieser Ebene ist es nicht entscheidend, ob Figuren mehr wissen als der Zuschauer und umgekehrt. Diese repräsentative Ebene ist nicht Ausgangspunkt zur Erschließung einer Szene, sondern Ergebnis bzw. ein Ziel der Analyse. So kann man das ,Figurenwissen“ auf einer ganz anderen Ebene ansiedeln: am Sehen und Hören der Zuschauerin, an der Bildgestaltung des Filmischen.

In der besprochenen Szene aus THE AwFUL TRUTH wird durch die Ausdrucksbewegung eine Relation in Gang gesetzt, in der Zuschauer ein multiperspektivisches Sehen und Vorstellen einüben, indem mal die Position der einen Figur, dann wieder die Perspektive der anderen Figur eingenommen wird. Doch dieses Perspektivieren ist kein Vorgang, der vom Bild zu abstrahieren wäre. Der basalste Verstehensprozess, der hier angesprochen war, hängt davon ab, ob sich bestimmte

56 Langer 1975, S. 153. 
Elemente des filmischen Bildes im Verlauf der Wahrnehmung trennen oder verbinden und wie sie durch die Zeitgestaltung aufeinander abgestimmt sind.

Die Analyse zeigt auf, wie das Sehen und Hören von filmischen Kompositionen den Empfindungsprozess sowie das Verstehen von Figuren und Handlungen bestimmt. Damit konnte eine basale Struktur von Narration in den Blick genommen werden. Aus dieser Sicht sind Figuren und filmische Welten nicht ein vom Bild abstrahierbares Geschehen. Vielmehr sind diese Prozesse an den Akt der Fiktionalisierung gebunden, an die Art und Weise, wie man als $\mathrm{Zu}$ schauer die verkörperte Wahrnehmung reflektiert.

Im Folgenden werde ich eingehender betrachten, welchen Status die Emotionsdarstellungen im Schauspiel in den Komödien haben und auf welche Weise das Gesicht in seiner Kommunikationsfunktion damit verbunden ist.

\subsection{Gefühle als tauschbare Gegenstände - Zur Kommunikationsfunktion des Gesichts}

\section{Verdinglichte Gefühle - MR. AND MRS. SMITH}

Das ununterlassene Exponieren von verbalen und nonverbalen Kommunikationsformen zeigt, dass Fragen nach Gemeinschaft und Sozialität das ureigenste Thema der Screwball Comedies sind, ob nun auf der Ebene von Paardyade oder Gruppenverbund. Man kann dies vor allem in den Milieustudien beobachten, wenn Z.B. in MY MAN GODFREY, THE PALM BEACH STORY, MIDNIGHT oder HOLIDAY ${ }^{57}$ die oberen Zehntausend parodistisch, fast wie in einem Verhaltensexperiment observiert werden. ${ }^{58}$ In diesen Filmen, die sich als Gesellschaftsanalysen lesen lassen, mag man besonders erkennen, wie sehr in den Komödien individuelle Gefühlswelten zu reinen Äußerlichkeiten werden, lästig wie eine Marotte, abstreifbar wie ein Kleidungsstück. Diese Hervorkehrung des Äußerlichen ist ein fester Topos im Komischen bzw. in der Komödientradition, man findet ihn z.B. bei Bergson wieder: „Komisch ist jedes Geschehen, das unsere Aufmerksamkeit auf das Äußere einer Person lenkt, während es sich um ihr Inneres handelt." ${ }^{\text {"59 }}$ Das Komische ist eine Angelegenheit, in der weniger das individuelle Empfinden im Vordergrund steht, als seine Rahmung, als die Situation, in der es entsteht. Bergson beschreibt dieselbe Beobachtung noch durch andere Formulierungen: „Wir lachen immer

57 MIDNIGHT (Mitchell Leisen, USA 1939); HOLIDAY (George Cukor, USA 1938).

58 Deleuze 1997 (1983), S. 215.

59 Bergson 1972 (1900), S. 40. 
dann, wenn eine Person uns an ein Ding erinnert.“60 oder: „Die Form will über den Inhalt triumphieren, der Buchstabe wetteifert mit dem Geist. “61

Die Screwball Komödien beziehen sich ebenfalls auf diese Eigenschaft von Komik: In den Szenen der streitenden Paare werden die Gesichtsbilder oft zu rhetorischen Floskeln, zu Zahlungsmitteln im Handel um Gefühle, Sexualität und Moral. Das Schauspiel besitzt eine gewisse Eigenständigkeit - exzentrische Verhaltensweisen -, um auf sich aufmerksam zu machen - doch Kamera und Montage lassen diese Art von individuellem Gebaren nicht zu und lenken die Aufmerksamkeit weniger auf den einzelnen Gesichtsausdruck als darauf, wie dieser sich im Kontext einer Gruppenansicht einfügt. Wie in den letzten drei Kapiteln gezeigt, findet in vielen Fällen eine Negierung des individuellen Emotionsausdrucks statt. ${ }^{62}$

Präsentierte Emotionsdarstellungen verwandeln sich in dinghafte Objekte. Durch kinematografische Bildakte beziehen sich Gesichter, aber auch Stimmbilder, Körperhaltungen und Gesten relational aufeinander; wie der Hut zum Schirm, die Zigarette zur Hand werden sie zu behandelbaren Sachen. Oder wie Georg Seeßlen zur Filmkomik generell resümiert:

Konsumierbar wird also jede Gefühlsregung, die als symbolische Darstellung veräußerlicht und verfremdet wird. So lassen sich im Genre des Komischen die Mißlichkeiten des Alltags genießen, mit einer kleinen Portion Masochismus, einer kleinen Portion Sadismus, aber ohne Gefahr für die Seele. ${ }^{63}$

Diese Verkleinerung dargestellter Emotionen zu popcorngroßen Dingen, die ,konsumierbar` bzw. handhabbar werden, bedeutet jedoch keine Abwesenheit der Affektivität der Zuschauer. Vielmehr bedeutet es, dass die Gefühle der Zuschauer weniger im Nachvollziehen oder Mitfühlen mit fiktiven Figurengefühlen begründet liegen. Das affektive Vergnügen besteht hingegen im Erleben einer höchst vitalen Gemeinschaft, gegen die sich die einzelnen Teilnehmer vehement sträuben.

Das Gefühl des Gemeinsamen kann man bereits auf einer perzeptiven Ebene ansiedeln, die nur für den Zuschauer existent ist. Ähnlich wie im Suspense, wo es eine Verbundenheit zwischen autonomer Kamerainstanz und Zuschauer

60 Bergson 1972 (1900), S. 44.

61 Bergson 1972 (1900), S. 41.

62 Ähnliches stellt Dana Polan im Zusammenhang mit HIS GIRL FRIDAY fest: „Thus, the Hawksian screwball film can entertain subjectivity - indeed, it can fully encourage subjectivity's representation - but only as a resistant force that has to be reduced down to the materiality of acting bodies.“ Dana Polan: The Light Side of Genius. Hitchcock's MR. AND MRS. SMITH in the Screwball Tradition. In: Andrew Horton (Hg.): Comedy/Cinema/Theory. Berkeley/Los Angeles 1991, S. 131-152, hier S. 135.

63 Seeßlen 1976, S. 13. 
gibt $^{64}$, besteht ein Aspekt des Vergnügens in der Screwball Comedy darin, das Schwingen mit einer spürbaren (kinematografischen) Instanz zu erleben, ein gemeinsames Wahrnehmen zu empfinden, das nur punktuell mit der Paar-Gemeinschaft in eins gesetzt werden kann.

Dargestellte Gefühle, ob als Emotionskarikatur ausgestellt oder durch das narrative Geschehen motiviert, werden oft so gezeigt als dürften sie sich nicht entfalten: Eine aufleuchtende Eigenheit in der Mimik, ein individualistischer Zug in der Körperhaltung, werden zwar sichtbar, sind aber nur kurz aus der Ferne zu sehen oder werden sofort kontextualisiert. Damit schließen die Komödien in Bezug auf ,das verdinglichte Gefühl' an verschiedene Strömungen der 1920er Jahre an, an die Neue Sachlichkeit ${ }^{65}$ oder an die objektbezogene Komik des Slapstick. ${ }^{66}$

Durch die Aufmerksamkeit auf das Äußerliche erleben wir beispielsweise in MR. AND MRS. SMITH eine handgreifliche Auseinandersetzung als komisch-kindliches Spiel und keineswegs als brutalen Übergriff. ${ }^{67}$ David (Robert Montgomery) ist Anne (Carole Lombard) ins Kaufhaus gefolgt, wo sie seit Kurzem als Angestellte arbeitet. Seine Überredungskünste, sie möge doch ihren Job aufgeben, fruchten wenig. Die Kamera selbst ist die Instanz, welche diesen Eindruck hervorbringt: Man sieht Davids strengen Blick, den entschlossenen Schritt vor dem Hintergrund kindlicher Gegenstände - kleine Hemdchen, ein Kinderbett, ein Karussell mit Plüsch-Schafen, der Schriftzug „Little Boy Blue“. David und Anne stehen in der Babywarenabteilung, getrennt durch die Ladentheke. Anne ignoriert seine Fragen und bietet ihm Windeln an, antwortet ihm in ihrer Rolle als Verkäuferin, übertrieben freundlich. Je eindringlicher er auf sie einredet, umso formeller wird ihre Service-Freundlichkeit. Durch die Ausstattung, das Schauspiel und die Kamera wird Davids insistierendes Gesicht verniedlicht.

Schließlich packt er Anne an beiden Armen und zerrt sie zu sich. Doch man nimmt in dem Moment nicht so sehr den Akt der Besitzergreifung wahr, als die

64 Greifenstein und Lehmann: Manipulation der Sinne im Modus des Suspense. In: CINEMA 58, Marburg 2013, S. 102-112.

65 So beschreibt Kappelhoff das neusachliche Motto als „verdinglichte Welt des Sozialen“, die in der „Subjektivität erst verfügbar geworden ist. Nicht die Klage des entfremdeten Menschen artikuliere sich in solcher Sinnlichkeit, wohl aber die Entlastung dessen, dem die empfindsame Seele auf die leichter Hand $\mathrm{zu}$ greifende Wohlgefälligkeit eines Reisesouvenirs geschrumpft ist.“ Kappelhoff 1994, S. 12.

66 Die Wurzeln dieser komödischen Reflexion einer Verdinglichung des Lebens liegen freilich in der Slapstick-Komödie und ihren Arten und Weisen, Mechanisierung und Massenproduktion zu reflektieren. Siehe Georg Seeßlen 1976, S. 49-50. Zum Mechanischen im Slapstick vgl. Jim Leach: The Screwball Comedy. In: Barry K. Grant (Hg.): Film Genre. Theory and Criticism. Metuchen 1977, S. 75-89, hier: S. 76.

67 TC: 0:33:36-0:37:36. 
Situation, in der sie sich befinden: Der Akzent wird vom Gefühlsausbruch und vom körperlichen Übergriff auf die soziale Situation im Warenhaus verlegt. Die Windeln fliegen wild umher, die ordentlichen Baby-Waren, lieblich drapiert, werden umgestürzt, von der Theke geräumt, es rumpelt und kracht. Dann sieht man gestrenge, genervte und peinlich berührte Blicke der Leute im Kaufhaus. Nicht das ruppige Zerren und Ziehen Davids an Anne wird hier von der Kamera ins Zentrum gerückt, sondern die Gegenstände des Kindlichen sowie die soziale Rahmung erscheinen relevant: Der Abteilungsleiter ermahnt die beiden voller Entrüstung; die Kunden drehen sich um, alle blicken das Paar an. Der individuelle Gesichtsausdruck von David wird in der Zurechtweisung und im gemeinschaftlichen Anblicken des Paares aufgelöst. David und Anne stehen mit dem Rücken zur Kamera aneinander zerrend. Verschwommen sieht man im Hintergrund wie sich ein Halbkreis von Menschen bildet, die ihre Augen auf sie richten. In der mittleren Raumebene des Bildes (in hoher Bildschärfe) sieht man den strafenden Blick, das mißbilligende Gesicht des Abteilungsleiters. Die Einstellung aus der Sequenz verdichtet den vorherigen Verlauf der Bilderfolge, ist ein szenischer Höhepunkt. In ihm kommt das ganze ausgearbeitete narrative Thema des unsicheren Ehestatus auf den Punkt. In dieser Mise-en-abyme-Struktur erfährt die Zuschauerin eine Komposition bildlicher Zentrierung. Das Paar sieht man halb mit dem Rücken zur Kamera, der strafende Blick des Abteilungsleiters setzt sich in den hinteren Bildebenen fort, in denen Menschen und deren Blicke nur schemenhaft angedeutet sind. Und doch: alle Augen liegen halbkreishaft auf dem Paar, wodurch Davids Festhalten ihrer Hände eine kollektive und bewertete Seite aufweist (Abb. 40).

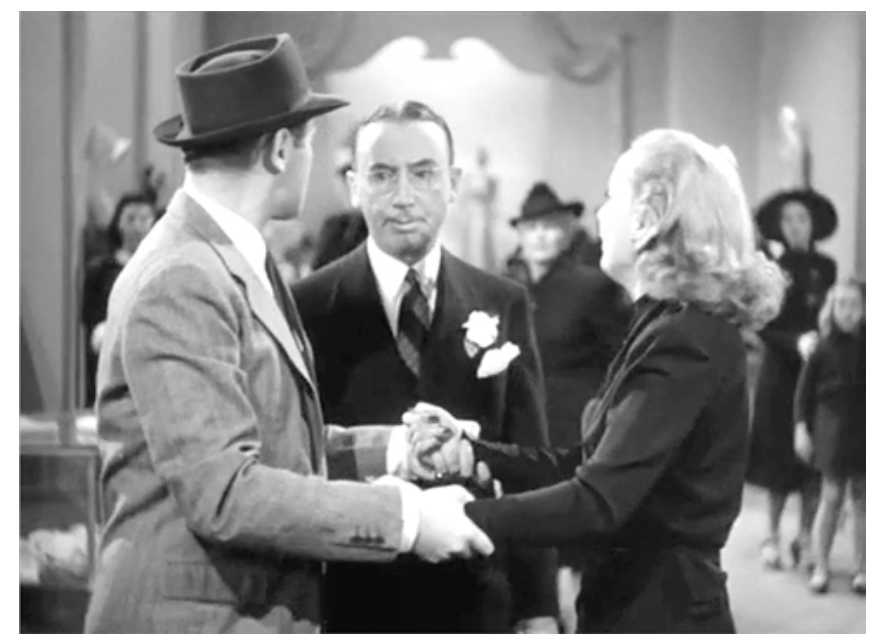

Abbildung 40: Bloßstellung vor einer Gruppe - MR. AND MRS. SMITH. 
Nicht nur das Zurücktreten vor der Situation, das Einnehmen einer Distanz „als unbeteiligter Zuschauer“, wie Bergson sagt, begünstige das Komische, sondern auch das Fehlen einer Sichtbarwerdung innerer, individueller Empfindungen der dramatischen Personen.

In der Szene aus MR. AND MRS. SMITH lässt sich diese Anordnung als Verstehensprozess und als metaphorisches Seeing As beschreiben: Ein Paar-Streit ist erfahrbar als lächerliches Kinderspiel um Dinge. Die Metapher kommt zustande, indem das Gesicht Davids und Annes nicht in der Inszenierung zentral gesetzt werden, sondern die Körper beider Schauspieler in einer Kadrierung mit alltäglichen Gegenständen, Sachen, Waren gegengeschnitten werden oder aber die Kamera aufzieht und dadurch das Verhalten rahmt, verkleinert, kontextualisiert. Mit dem Fokus auf kindliche Gegenstände wird das Paar in seinem Streit einer Lächerlichkeit preisgegeben, welche die sie umschließende Menge, die stummen Zuschauer, verächtlichen Blicke und den strengen Verweis als erwachsene Autorität kennzeichnet, während das Paar in seinem unbeholfenen Gerangel und der sinnlosen Anhäufung von Gegenständen wie zwei Kinder erscheint, welche die Maßregelung verdient. Nicht das individuelle Empfinden (Davids oder Annes Ärgernisse) wird nachvollziehbar, sondern ein soziales Gefühl: Peinlichkeit und Scham aufgrund der Bloßstellung vor der Öffentlichkeit sind hier deutlich inszeniert.

\section{Geselligkeit und Taktgefühl}

Wie bereits angesprochen sind die Gefühlsdramaturgien der Screwball Comedies zentral auf Erheiterung, auf Lust und Genießen ausgerichtet. Doch neben diesen positiven Gefühlen werden auch Scham, Peinlichkeit und Schadenfreude immer wieder nachvollziehbar. ${ }^{68}$ Die Filme kreisen mit ihrer Inszenierung gemeinschaftlicher Gefüge und sozialer Gefühle um gesellschaftliche Verhaltenscodes, die befolgt und normiert oder aber überschritten bzw. ausgehebelt werden.

Der Begriff der Geselligkeit nach Georg Simmel ist situiert in einem Verständnis für Abendgesellschaften, die von den bürgerlichen Schichten in Europa seit dem siebzehnten Jahrhundert als Salons, Lesezirkel (u.a.) ausgerichtet wurden. Der Begriff umfasst einen Bereich des Sozialen, der auch im Mittelpunkt der Brüche und Subversionen der Komödien steht. Kommt man in einer Abendgesellschaft, zu einem Essen zusammen, dann dient das Treffen der Zufriedenheit aller Beteiligten. Gerade deshalb, so betont Simmel in seinem

68 Auf der Ebene der fiktionalisierten Gefühle, die Schauspielerkörpern zugeschrieben werden, aber zum Teil auch auf der Ebene der Zuschauergefühle. 
Aufsatz zur Geselligkeit, sei es notwendig, dass alle sich auf gleicher Augenhöhe und mit einer Spur Diskretion begegneten, dabei sei ein gewisses Taktgefühl von Nöten:

[...] das Allerpersönlichste des Lebens, des Charakters, der Stimmung, des Schicksals hat gleichfalls im Rahmen der Geselligkeit keinen Platz. Es ist taktlos, bloß persönliche Stimmung und Verstimmung, Aufgeregtheiten und Depressionen, Licht und Dunkelheiten des tiefsten Lebens in die Geselligkeit mitzubringen. Wo eine gesellig begonnene Vereinigung - und keineswegs nur eine oberflächlich gesellschaftliche und konventionelleschließlich um so individuelle Werte zentriert, verliert sie den Charakter der eigentlichen Geselligkeit und wird zu einem durch einen Inhalt bestimmten Zusammensein [. . .]. ${ }^{69}$

Das Gesellige - so Simmel - zeichne sich gerade nicht dadurch aus, dass man über ernste Themen diskutiere, dass es inhaltsbezogene Auseinandersetzungen gebe. Der Geselligkeit hafte keine gesprächsbedingte Tiefe an, vielmehr werde sie von Gruppen genutzt, um sich zu verbinden. Ein geselliger Abend werde nicht durch das Hervortun Einzelner begünstigt, sondern durch einen respektvollen, wohlwollenden Umgang miteinander. Doch dieses Verhalten sei eine „künstliche Welt ${ }^{\text {“70 }}$, denn die einzelnen Teilnehmer einer Abendgesellschaft müssten eine Art Bühnenstück aufführen, um die sozialen Ungleichheiten, die untereinander herrschen (die verschiedenen Schichten, der gesellschaftliche Stand) zu glätten. Simmel bezeichnet die „Geselligkeit als die Spielform der Vergesellschaftung““: ${ }^{71}$

Indem Geselligkeit also mit dem Charakter der Kunst oder des Spieles vollzogene Abstraktion der Vergesellschaftung ist, fordert sie die reinste, durchsichtigste, am leichtesten ansprechende Art der Wechselwirkung, die unter Gleichen; sie muß sich, um ihrer fundamentalen Idee willen, Wesen fingieren, die von ihrem objektiven Inhalt so viel abgeben, die nach ihrer äußeren wie inneren Bedeutung so modifiziert werden, daß sie als gesellige gleich sind und ein jedes die Geselligkeitswerte für sich nur unter der Bedingung gewinnen kann, daß die anderen, mit ihm wechselwirkenden, sie ebenso gewinnen. Sie ist das Spiel, in dem man ,so tut', als ob alle gleich wären, und zugleich, als ob man jeden besonders ehrte. ${ }^{72}$

69 Georg Simmel: Soziologie der Geselligkeit. (1911) In: ders.: Gesamtausgabe in vierundzwanzig Bänden. Bd. 1: Aufsätze und Abhandlungen 1909-1918, hg. von Rüdiger Kramme, Angelika Rammstedt und Ottohein Rammstedt. Frankfurt a. M. 2001, S. 177-193, S. 181.

70 Simmel 2001 (1911), S. 183.

71 Simmel 2001 (1911), S. 180. Dabei hat Georg Simmel das, was die verschiedenen gesellschaftlichen Anlässe von Gruppenbildungen gemeinsam haben, als gefühlsmäßige Verbundenheit bestimmt, wenn er das Aufgehen des Individuums in der Gruppe als für den Einzelnen befriedigendes Ereignis zusammenfasst: „alle diese Vergesellschaftungen [werden] von einem Gefühl dafür, von einer Befriedigung daran begleitet, daß man eben vergesellschaftet ist, daß die Einsamkeit des Individuums in ein Zusammen, eine Vereinigung mit anderen aufgehoben ist“, ebd., S. 178.

72 Simmel 2001 (1911), S. 184. 
Die Geselligkeit verursache, dass man die soziale Gleichstellung aller Beteiligten fingiere, um sich begegnen zu können, das gemeinsame Einverständnis einer Gruppe an einem Abend, eine Zusammenkunft als Fiktion einer Gemeinschaft zu imaginieren. Dies beinhalte auch, dass eine gesellschaftlich einflussreiche Person sich gegenüber einer weniger einflussreichen Person bescheiden verhalte, dass eine bekannte Persönlichkeit zurückhaltend auftrete etc. Taktlosigkeit ist bei Simmel die Gefährdung dieser Verbindung, in der jeder gleich zu sein scheint. ${ }^{73}$ Dabei seien die Gefühle, die solche Prozesse des Geselligen begleiten, Freude, Entlastung oder Lebendigkeit. ${ }^{74}$ Das Erleichternde, das von aller Schwere Enthobene sieht Simmel für das Gesellige als grundlegend an. Das Gesellige befreie, erheitere und erleichtere, da es als Spiel genossen werden kann. Freilich ist der Begriff ein historisch und kulturell spezifisches Konzept: eine Art Etikette, ein Verhaltenskodex bürgerlicher Schichten des neunzehnten und zwanzigsten Jahrhunderts, eine Idee, die sich abgewandelt für spätere gesellschaftliche Überlegungen reflektiert etwa bei Plessner oder Goffman wiederfindet. ${ }^{75}$

Viele der untersuchten Komödien handeln von Geselligkeit im Simmelschen Sinn, indem sie die Gleichheit aller Beteiligten in einer Art Spielform darstellen und so gesellschaftliche Hierarchien als überwindbar kennzeichnen. Dieser Grundgedanke bei Simmel zeigt auf, dass demokratische Grundprinzipien, die Gleichheit aller, auf eine Verhaltensebene gebracht werden kann und so soziale Hierarchien unsichtbar zu werden scheinen. Es ist diese Ebene einer Gleichheit, welche die Screwball Komödien zum Teil zur Anschauung bringen. Gleichzeitig handeln die Filme oftmals auch von einer gegensätzlichen Idee, wenn gerade großbürgerliche Abgrenzungen zum Ausdruck gebracht werden (etwa in THE PHILADELPHIA STORY oder THE AWFUL TRUTH). Ein fast theatrales Spiel wird zudem genossen, wenn man Figuren dabei zusieht, wie sie die Fesseln einer sozialen Konvention abstreifen. Insofern geht es in den Komödien auch um Taktlosigkeit; man erfährt, wie sich eine exzentrische Gebärde hervortun will, wie sie aber als solche ausgebremst wird. Immer wieder sieht man ein Ringen um das Individuelle ausgestellt, das in eine gemeinschaftliche Form zurückgeholt

73 „[S]obald die Diskussion sachlich wird, ist sie nicht mehr gesellig“, Simmel 2001 (1911), S. 190.

74 Simmel 2001 (1911), S. 183.

75 Bei Plessner lässt sich Simmels Einfluss nicht nur in seinem Text Lachen und Weinen wiederfinden, wo er die freudigen Lachanlässe mit ähnlichem Vokabular beschreibt, sondern auch in "Zur Anthropologie des Schauspielers" sowie in seinem politischen Text Grenzen der Gemeinschaft, worin man Anlehnungen an Simmels Überlegungen finden kann. 
wird. Dabei ist in den Komödien das gesellige Spiel um die „Art der Wechselwirkung, die unter Gleichen“ (s.o.) auf einer Ebene angesiedelt, welche zuerst eine starke Ungleichheit etwa zwischen den bürgerlichen und proletarischen Schichten sichtbar macht. Immer wieder wird eine Figur aus ärmlichen Verhältnissen aus Zufall oder Kalkül in die Kreise der Upper Class eingeschleust, wo sie meist einen anderen Namen annimmt, sich anders kleidet und spricht. Immer wieder wird durch Verkleidung eine bestimmte Gesellschaftsschicht in ihren sozialen Codes, Regeln, Normen und ihrem Habitus analysiert. Die soziale Zugehörigkeit wird auch vielfach so inszeniert, als sei sie über reine Äußerlichkeiten und Statussymbole definiert, welche man sich, schlüpft man nur in die Rolle, sofort zu eigen machen kann. Man erkennt anfangs einen großen Abstand zwischen narrativen Figuren, die bestimmten Schichten zugeordnet werden. Doch wird dieser Abstand (z.B. zwischen Arm und Reich) durch die Maskerade der Figuren als Spiel, als Code, als Konstruktion entlarvt. Indem eine arme Frau die Welt der Reichen betritt und sich als Gräfin ausgibt (MIDNIGHT) oder auch umgekehrt, ein reicher Mann als verarmter Obdachloser lebt (MY MAN GODFREY) wird die soziale Kluft dramaturgisch verhandelt und ist als beweglich und überwindbar zu erfahren. Ungleichheiten werden für einen Moment ausgehebelt, wenn z.B. der Taxifahrer wie ein Graf behandelt wird (MIDNIGHT) oder wenn das Mädchen von nebenan für die Tochter des Multimilliardärs gehalten wird (EASY LIVING ${ }^{76}$ ). Jedoch kann man in den Komödien auch das negative Kippbild dessen beobachten: die hinter vorgehaltener Hand erzählte Intrige, das heuchelnde Lächeln, das hochmütige Lachen über jemanden, die Verstellung, die höfischen Codes. ${ }^{77}$ Die steifen Rituale der Upper Class werden immer wieder auch in ihrer elitären Unzugänglichkeit ausgestellt (HOLIDAY, PLATINUM BLONDE ${ }^{78}$, MY MAN GODFREY).

\section{Die pragmatische Komödie - Kompromiss und Ökonomie}

Die Screwball Comedy wird meist als Liebeskomödie dargestellt, dass es sich dabei um das Romantische handelt, wird aufgrund des Plots oftmals selbstver-

76 EASY LIVING (Mitchell Leisen, USA 1937).

77 In der höfischen Geselligkeit habe sich die Etikette ausgebildet, die auf eine Regelhaftigkeit im Verhalten und in der Kommunikation abzielte und dadurch zu einer erstarrten Form wurde. Simmel 2001 (1911), S. 191.

78 PLATinum BLOND (Frank Capra, USA 1931) 
ständlich angenommen. ${ }^{79}$ Doch meine bisherigen Analysen zeigen, dass die Komödien weniger von romantischer Liebe handeln als ein pragmatisches Verständnis von Beziehung versinnlichen. Denn innerhalb der Paarinszenierungen werden die Kommunikationsweisen auf eine Art ins Bild gesetzt, wodurch sie zum Teil instrumentalisiert erscheinen, als wären sie rhetorische Mittel. Schon die narrativen Muster geben darüber Aufschluss: So stellt der Plot von Cinderella einen wichtigen Ausgangspunkt einiger Erzählungen dar. Dabei handelt es sich nicht immer nur um Geldfragen, die aufgrund der großen Depression und ihren Folgen Utopien und Wünsche thematisieren. Die Screwball Comedies handeln davon, wie wirtschaftliche Prinzipien Einzug erhalten in den zwischenmenschlichen Bereich. Nicht nur verbale Zuspitzungen kehren dies hervor; die Ökonomisierung des Zwischenmenschlichen zeigt sich auch in einer ästhetischen Praxis, wobei die Gesprächsformen als strategisch, als zweckgerichtet erkennbar werden: die Kommunikationsfunktionen des Gesichts bringt dies hervor. In BLUEBEARD'S EIGHTH WIFE treibt die Braut (Claudette Colbert) in einer Auktion den Preis für die Heirat in die Höhe - zwischen monetären und moralischen Werten, um ihrem Gatten eine Lehre zu erteilen. In THE LADY EVE ${ }^{80}$ verschafft sich eine Falschspielerin (Barbara Stanwyck) mit gezinkten Karten echtes Geld; sie wird zu einer Schauspielerin, welche echte Gefühle in falsche verwandeln kann. In TWENTIETH CENTURY buhlt ein Regisseur um die Gunst seiner Muse, ohne die er keinen Erfolg mehr im Theater hat. Dabei werden Interessen so miteinander verquickt, dass offenbleibt, ob die ökonomischen oder amourösen Gründe für ein Zusammensein überwiegen: Das Unterzeichnen des Arbeitsvertrags wird zum Grund der Erneuerung des Liebesverhältnisses. Auch in HIS GIRL FRIDAY handelt Hildy (Rosalind Russell) mit ihrem Exmann (Cary Grant), der gleichzeitig ihr ehemaliger Chef ist. Walters Umwerben von Hildy stellt sich weniger als selbstlose Liebesbekundung dar, denn als taktische Überzeugungsarbeit zum Zweck knallharter, ökonomischer Zwänge. So sagt Walter zu Hildy: „If you won’t do it for love, how about money?!“ Die Gesichtsbilder, die inszenatorisch einen Tauschhandel untereinander eingehen, sind ähnlich beschaffen, sie changieren zwischen Verführung und Kalkül.

In einer solchen Lesart lässt sich das gesamte Genre der Screwball Comedy auf den Nenner des Sinnbilds von der Ehe als Ökonomie der Affekte bringen. In BLUEBEARD'S EIGHTH WIFE sagt Michael zu Nicole: „Love and business is just the

79 Z.B. bei Duane Byrge: „Like most Hollywood products then and now, a screwball comedy was at heart a love story. “ Duane Byrge und Robert M. Miller: The Screwball Comedy Films. A History and Filmography, 1934-1942. Jefferson 1991, S. 2.

80 the LADY EVE (Preston Sturges, USA 1941). 
same, you have to gamble, you have to take chances." ${ }^{81}$ Doch dieses Sinnbild ist nicht allein auf der Ebene des Dialogs angesiedelt, sondern konstituiert sich vielmehr in den expressiven Formen des dargestellten Schauspiels und ihrer filmischen Einbettungen. Das gewöhnliche und das posierende Gesicht sind dafür paradigmatischen Bildformen; darüber hinaus stellen die Komödien das Aushandeln von Geschlechterpositionen jeweils in den sinnlich-konkreten Zusammenhang des Tauschs von Gesichts- und Stimmbildern: Ein vokales Sich-Überbieten geht einher mit dem Ringen um eheliche Macht- und Besitzansprüche; der neutrale Gesichtsausdruck wird strategisch als Pokerface eingesetzt; das Erringen des letzten Worts entscheidet schließlich über Sieg und Niederlage im Streitgespräch. Was in den komischen Szenen der Screwball Comedies als Tauschgeschäft angeboten wird, sind affektive Überspitzungen in ihrer Darbietung selbst. Die zur Schau gestellten Emotionen erscheinen nur mehr als äußerliche Gegenstände, die einander wie Frage und Antwort bedingen. In HIS GIRL FRIDAY wird Cary Grants beiläufige Geste eingetauscht in Russels abweisenden Blick. Ihre Eigensinnigkeit wechselt in seine Arroganz. Ihre Zärtlichkeit wird eingelöst durch seinen Charme. Das mit der Paargeste einhergehende Gefühl kann sich ganz unterschiedlich ausprägen: als Zusammengehörigkeit, als gemeinsames ,Schwingen', als Gegensätze, die als Einheit erlebt werden, als Konflikt zwischen Einzelkörper und Gemeinschaftlichem, als Vitalitätsempfinden etc. In diesem Sinn sind die Paargeste, das affektive Stimmbild sowie das gewöhnliche und posierende Gesicht für die Screwball Comedy beispielhafte Inszenierungsprinzipien, die sich als Grundform der Gefühlsgestaltung (u.a. der Wir-Gefühle) beschreiben lassen. Andererseits gibt es in den Komödien auch ganz andere Modi des Gefühls, welche sich zu den Wir-Gefühlen komplementär verhalten.

\section{Paradoxe Empfindungen - Der rasche Wechsel unterschiedlicher Gefühlsmodi}

$\mathrm{Zu}$ dem vitalen Wir-Gefühl der Paargeste oder auch der Gemeinschaftsgeste kommt ein weiterer Gefühlsmodus dazu, der durch das übertriebene Spiel, das die Schauspieler ausführen müssen, gelenkt wird. Dieses ist ein Fingieren, wobei das Zuschauerempfinden darauf ausgerichtet wird, das Uneigentliche zu erleben: das Falsche im Lächeln, das Übertriebene im Gruß, das absichtliche Einsetzen einer Geste. Man erlebt oftmals ,meinende Gesten“ und posierende Gesichter, das heißt Formen des Verhaltens, in denen es um ein gespieltes 
Gefühl oder eine bestimmte gesellschaftlich erwartbare Reaktion im Ausdrucksgeschehen geht. Dieses Prinzip ist sehr ausgeklügelt, da in keinem Moment die klassische Diegese gebrochen wird. Vielmehr ist das Rollenspiel oder die Maskerade immer auch in der narrativen Dramaturgie begründet.

So etwa in HIS GIRL FRIDAY, als Walter (Cary Grant) Hildys (Rosalind Russel) Verlobten Bruce (Ralph Bellamy) kennenlernt. Am Eingang der Redaktion begrüßt Walter zuerst den Falschen, einen älteren Herrn, dann erst Bruce (Abb. 41). Man erlebt am Schauspiel Grants eine Absichtlichkeit in der ausgeführten Showeinlage. Seine Performance ist auch danach im Modus des Slapsticks gehalten, wenn er zu Bruce übergeht und anstatt seinem Gegenüber die Hand zu schütteln zur Begrüßung den Griff des Regenschirms ergreift, als wäre es die Hand. Dabei erlebt man nicht, dass Cary Grant übertrieben spielt, sondern man erlebt die Figur Walter, die etwas mit ihren Gesten bezweckt. In dieser Szene wird ein gespaltener bzw. sich durchkreuzender Bildraum aufgemacht. Bevor Walter Bruces Regenschirm schüttelt, sieht man eine Einstellung mit Walter, Bruce und dem älteren Mann. Zwischen den Einstellungen mit den drei Männern sieht man immer wieder Hildy in einer Einstellung als Zuschauerin des Spektakels, sie beobachtet amüsiert, wartet ab (Abb. 41).
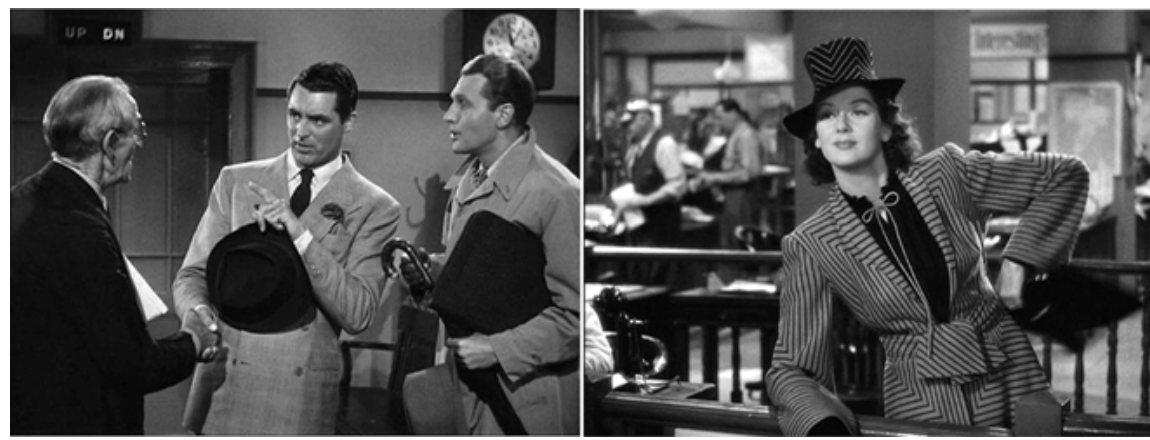

Abbildung 41: Das Spiel und die Zuschauerin - HIS GIRL FRIDAY.

Der Bildraum ist für uns Zuschauer in einer Zweiteilung erfahrbar. Da ist auf der einen Seite Walters ,Bühne‘: man sieht die drei Männer in einer Kadrierung; auf der anderen Seite befindet sich das ,Publikum‘, Hildy, die lächelnde Zuschauerin, mit der wir als Zuschauer das Beobachten teilen. So überkreuzen sich diese Bild-Aufteilungen innerhalb einer Montage und teilen sich auf in 1. Akteure und Beobachterin bzw. Bühne und Publikum (durch die Kadrierungswechsel: die drei Männer + Hildy), sowie 2. in das Paar (Walter und Hildy, die von der gespielten Gestik Kenntnis zu haben scheint) und die 
Ahnungslosen (Bruce und der ältere Mann). Dies hat alles erst auf fiktionalisierter Ebene mit einem Wissensvorsprung zu tun. Zuvor ist es einfach das Sehen einer bewegungsmäßigen Verbindung. Das Zuschauererleben spannt sich an dieser schadenfreudigen Überkreuzung auf; so sieht man ernsthafte Gesichter, die nicht zu verstehen scheinen, worauf sich Walters Verhalten bezieht. Doch als Zuschauerin begreift man dies allein durch die heimliche Lust, selbst gewissermaßen exklusiv die verborgene und nur subtil erfahrbare Verbindung des Paars in einem Rollenspiel zu erleben, mit Hildy Zuschauerin zu sein. Die Art und Weise, wie Hildy als Zuschauerin Walters Verhalten mimisch kommentiert, hebt für uns Zuschauer erst das Bühnenhafte hervor. Der Aspekt der Schadenfreude als Zuschauergefühl ist nicht grundlos, sondern basiert vielmehr darauf, an der Verbindung des Paars teilzuhaben. Die Verbindung konstituiert sich aus minimalen mimischen Reaktion Hildys auf Walters Bewegungen und stellt demnach eine Bewegungskongruenz in unterschiedlichen Einstellungen her. Solche Übereinstimmungen von Bewegungsqualitäten sind die subtile Verbindung auf der Ebene des audiovisuellen Bildes, die wir als Zuschauer verkörpert spüren, die wir jedoch in erster Linie narrativ den Figuren zuschreiben (Walter und Hildy). In der Screwball Comedy geht es darum, Vergnügen dabei zu empfinden, eine bestimmte Dimension des menschlichen Verhaltens als Täuschung, Trick oder Plan zu entlarven.

Der Schadenfreude übergeordnet sind Überlegenheitsgefühle, welche an eine merkliche Instanz gebunden sind: an die Kamera. In manchen Szenen ist ein explizites ,Nicht-Reagieren' des Kaders auf exaltierte Gesten beobachtbar. Die Ansicht bleibt distanziert, andauernd, es geschehen keine umfassenderen Bewegungen des Kaders mit den Schauspielern. Hier scheinen die individuellen Emotionsausdrücke zum Teil ins Leere zu laufen. Was man während dieser Augenblicke erfährt, ist eine spürbare wahrnehmungsmäßige und emotionale Distanz zum Geschehen, die von der Kamera-Instanz ausgeht, wodurch individuelle Emotionsausdrücke klein gehalten werden; zudem werden dadurch auch bildliche Entsprechungen eines Lächerlichwerdens etabliert, die Inszenierung scheint eine Art „Seht bloß!“ zu artikulieren, wenn etwa von einer nahen Einstellung sehr plötzlich distanziert wird; dann sieht man dabei zu, wie eine Art Entblößung vor der Öffentlichkeit stattfindet, wie sich eine Menschengruppe zusammenballt, die dem Spektakel des Paars zusieht. (So etwa in MR. AND MRS. SMITH, wenn nach der Kaufhausszene (s.o.) das Paar von Ordnungshütern herausbegleitet wird und sich um das Paar eine Menschentraube ringt, woraufhin ein Polizist schließlich den privaten Streit schlichtet.) Letzteres 
kann neben dem Gefühlsmodus der Schadenfreude auch Scham affektpoetisch gestalten. $^{82}$

Das Zueinander-Müssen, das Zu-Einander-Streben, das die Kadrierung als Instanz zu entscheiden scheint, kann sich in seiner Bildform auch vom freudigen Paar-Modus hin zu einer kalten, engenden Käfig-Ansicht transformieren. Hier findet das überlegene ,Lachen über‘, die „Anästhesie des Herzens“ (Bergson) ${ }^{83}$ tatsächlich eine Entsprechung (Abb. 42).

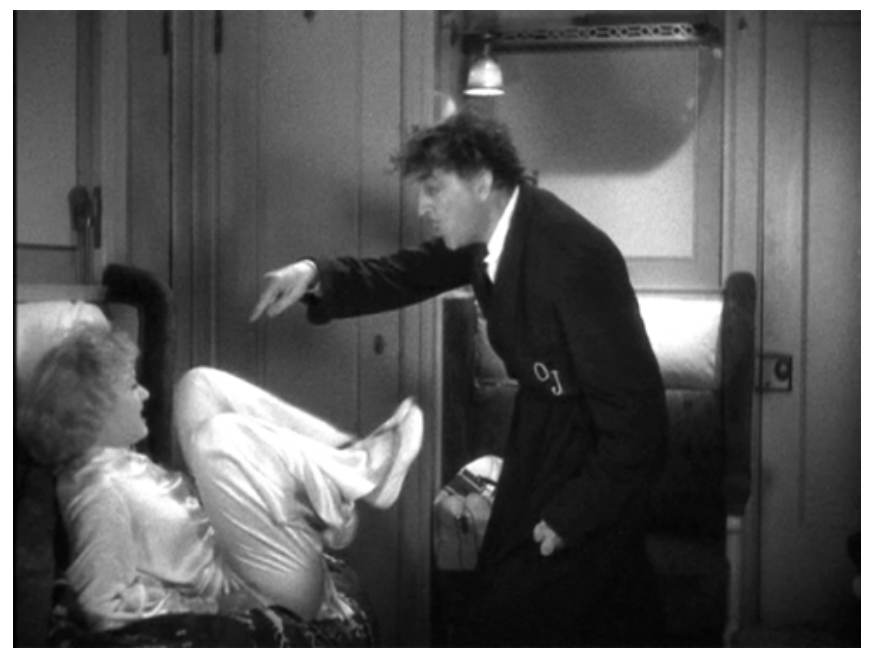

Abbildung 42: Die Dauer des Kaders mit expansiven Schauspielbewegungen als engende Rahmung - TWENTIETH CENTURY.

In TWENTIETH CENTURY rahmt die Kadrierung das Paar mitunter auf eine Weise, in der das Bild von der Paareinheit zu einer oszillierenden Spannung wird, indem man die geheimen und subtilen Gesten der Vertrautheit sieht, die später zu einem zur Ausweglosigkeit erstarren Mechanismus werden. Indem die Schnittfrequenz reduziert wird und lange Einstellungen vorherrschen, wobei die einzelnen Figuren in ihren Äußerungsakten weniger stark hervorgehoben werden, nimmt sich die

82 Freilich ist eine solche Affektpoetik zwar strukturell angelegt, muss sich aber nicht in jedem Zuschauersubjekt in der selben Intensität ausprägen. Vielmehr ist auch das periphäre Erleben eines historisch-kulturell situierten Gefühls möglich. Dieser Aspekt beleuchtet die Historizität audiovisuell hervorgebrachter Affizierungsweisen, welche die Filme (in Inszenierungsmustern gespeichert) an den jeweiligen Zuschauerschaften auf der Ebene der Erfahrung jeweils aktualisiert hervorbringen. Siehe Kappelhoff 2004 und 2016.

83 Bergson 1972 (1900), S. 13. 
Kamera zurück und bleibt in einer permanenten Rahmung in mittlerer Distanz; es herrscht ein kalter und engender Blick auf das lebendige Geschehen der Paarinteraktion.

Ein weiterer Gefühlsmodus tritt hinzu: Dieser ist an das Erleben von Sentimentalität gebunden. Es gibt in den Komödien immer wieder kurze Momente, welche auf das Gewahrwerden einer individuellen Empfindsamkeit abzielen. In der bereits beschriebenen Eingangsszene in HIS GIRL FRIDAY ist der Moment der Sentimentalität nur sehr kurz. Indem er sich so stark vom Rest der Szene unterscheidet, stellt er eine Art Betonung oder Gewichtung in der Sequenz dar. Betrachtet man die Ausdrucksbewegungseinheiten der Szene ${ }^{84}$, dann lässt sich feststellen, dass dieser Moment, dieses kurze Antippen eines melodramatischen Modus als dramaturgischer Höhepunkt der gesamten Sequenz dient, auf den alles Vorhergehende zuläuft. Nachdem das Paar sich unentwegt gestritten hat, platzt es aus Hildy heraus: „Look at this: It's an engagement ring!“. Sie streckt ihm ihre Hand mit dem Ring am Finger hin, beide schweigen. Der Kader springt plötzlich nahe heran, beide sind in der Zweiereinstellung zusammen, Grant blickt nachdenklich, Russell ist ernst. Die Rede und das mimische Spiel verlangsamen. Das Empfinden einer Bedeutsamkeit, einer Tiefe macht sich breit. Für einige Sekunden herrscht ein Bedauern, ein Innehalten, ein Gewahrwerden (Abb. 43).

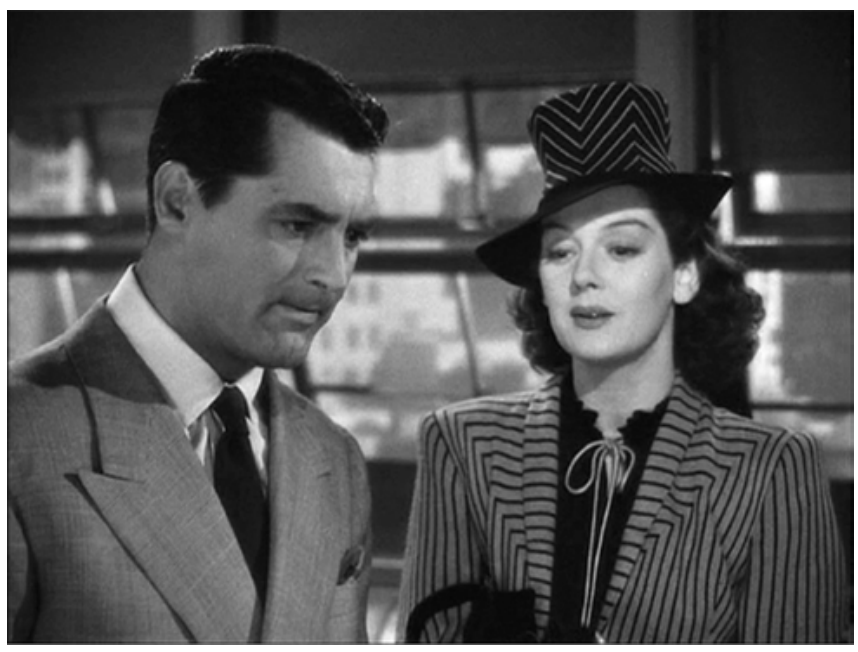

Abbildung 43: Das kurze Aufblitzen einer individuellen Empfindung in HIS GIRL FRIDAY.

84 Siehe Kapitel 4.3. 
Die Nahaufnahme ist eine Art Innehalten und rückt für einen kurzen Augenblick das subjektive Empfinden in den Vordergrund. Das Gesicht Grants will nun nicht mehr bedeuten, ist nicht mehr objekthaft, meint in seiner Regung nichts als sich selbst, jedoch stets im Verbund mit einem zweiten Gesicht. Für den Zuschauer ist diese Pause zentral. Alle vorherigen und darauffolgenden Scherze, Streitpunkte und Missverständnisse beziehen sich nicht mehr auf das Exponieren vielfältiger Emotionsregister, mit denen das Gegenüber umworben, getäuscht und gereizt wird, sondern auf eine in den Gesichtern aufscheinende Unwiederbringlicheit. Doch auch dieses Aussetzen der Rede dauert nur wenige Sekunden an, wird nur angespielt, nur für wenige Augenblicke dargeboten, bevor es wieder mit Rasanz weitergeht. Der Kürze entsprechend ist der hervorgehobene Moment als affektives Phänomen auch nur oberflächlich erfahrbar, da es zeitlich nicht andauert.

Dabei ist die angesprochene Kürze und Flüchtigkeit der verschiedenen affektiven Ansprachen von großer Relevanz, denn es macht gerade das Genre und seine Affektpoetik aus: Nicht die Dauer der Inszenierung eines Affekts über mehrere Minuten begründet eine Szene, sondern das Changieren vielfältiger affektiver Modi: vom flirrend-berauschenden und eleganten Wir-Gefühl der Paargeste über die geheimnisvolle Zeugenschaft; vom schadenfreudigen „Seht bloß“ bis hin zur grausam-einengenden Käfig-Rahmung. Gerade der rasche Wechsel dieser Modi erzeugt die Erheiterung, das Wahrnehmen von Vitalität, Enthobenheit und erleichternder Distanz im Zuschauergefühl. Dieses Durchlaufen der unterschiedlichen Gefühlsmodi amüsiert und entlastet, da die hohe Intensität und Schwere einzelner dauernder Affizierungen vermieden wird.

All diese Modi sprechen den Zuschauer in einem kurzen Augenblick an, doch dann ist dies auch schon vorüber. Kürze, Plötzlichkeit und die Wechsel der Bewegungsqualitäten sind die Charakteristika affektiver Verkörperung in der Screwball Comedy. Eine solche Praxis hat kulturgeschichtliche Vorläufer. Schon im Theater der Aufklärung beschrieb man den affektiven Charakter der Komödie als flatterhaft. Albine dazu aus „Der Schauspieler“:

In den Bezirk des Trauerspiels gehören nur sehr wenige Leidenschaften, Liebe, Haß, Ehrgeiz, welche noch dazu in dem Schrecklichen und Traurigen alle mit einander übereinkommen. Die Komödie hingegen schließt keine einzige Leidenschaft aus, und diese alle muß der Schauspieler annehmen und von einer auf die andre überspringen können. ${ }^{85}$

Während das Trauerspiel als an wenige tiefe Gefühle gebunden beschrieben wird, gilt für die Komödie Gegenteiliges: Leidenschaften springen über, dabei kann der Schauspieler alle Gefühlsschattierungen annehmen, er muss sie

85 Nach Gotthold Ephraim Lessing: Theatralische Bibliothek. Berlin 1754, S. 215. 
nur geschickt $\mathrm{zu}$ verbinden wissen und nie $\mathrm{zu}$ lange bei einer verweilen. Im Falle des Theaters der Aufklärung sind hier nur die Schauspielerkörper angesprochen. Im Falle der hier untersuchten Filme sind es die Zeitmuster filmischer Expressivität. Wenn die Tempi der Bewegung sich so rasant wandeln, nie verweilen, nie stehenbleiben, dann ist dies jedoch nicht allein eine Sache der Geschwindigkeit. Was in den gefühlsmäßigen Adressierungen der Komödien geschieht, ist vielleicht damit zu begreifen, was Plessner mit der Oberflächlichkeit des Lachens ${ }^{86}$ angesprochen hat, was allerdings keine ästhetische Wertung ist. Die extreme Flüchtigkeit der Affekte durch das kinematographische Bild setzen auf die Wandlungsfähigkeit: Nicht die Vertiefung eines Gefühls ist Gegenstand der Inszenierung, sondern es wird immer wieder ein Gefühlsmodus angespielt, doch dann elegant in einen anderen transformiert. Dadurch leuchten Gefühlsdarstellungen punktuell auf, doch da sie keine Zeit haben sich zu entfalten, werden sie als Skizze erkennbar, jedoch nicht einzeln nachvollziehbar. Eine solche zeitliche Karikatur der emotionalen Darstellungsmodi lässt die Gefühle selbst schließlich zu Gegenständen schrumpfen. Der Zusammenhang zwischen Gegenstand und Gefühl ist jedoch kein Selbstzweck, er speist im Modus der Komödie erst auf einer höheren Ebene die heiteren Zuschauergefühle: Enthobenheit; Freude und Erleichterung sind nach Plessner Resultate solcher Distanznahmen im Lachen. ${ }^{87}$

Die Musik im Vorspann von HIS GIRL FRIDAY verdeutlicht das Prinzip der Wechselhaftigkeit der Gefühlsdarstellungen als Kurzform. Darin wird deutlich, dass Tempowechsel für die Erzählung aber vor allem für die heiteren Zuschauergefühle eine zentrale Bedeutung haben. Im Vorspann setzt mit dem Sichtbarwerden der Columbia-Freiheitsstatue ein triumphales, marschähnliches, bläserdominiertes Motiv mit aufsteigenden Tönen ein. Als das Bild in die Credit-Sequenz überblendet, hält die Musik kurz inne. Sobald die Namen Cary Grant und Rosalind Russell erscheinen, ertönt eine zunächst schritthaft-gemäßigte Tonfolge abermals nach oben aufsteigend (romantisch). Mit dem Titel „His Girl Friday“ im Bild wandelt sich die Musik zum Haupt-Motiv mit swinghaftem Tempo: Die Bläser und Streicher spielen melodisch höhere Töne, maximal leicht, rasch und beschwingt. Doch die Melodie wird nicht bis zum Ende gespielt. Nach wenigen Sekunden unterbricht ein anderer musikalischer Charakter die Musik: Tiefere Töne und eine starke Rhythmisierung sind zu hören (Wiederholung der Melodie in einer anderen Tonart), wenn die Namen der Nebendarsteller zu lesen sind. Schließlich drängt sich das Hauptmotiv wieder vor. Am Schluss werden nochmal alle angespielten Musik-Motive hintereinander kurz angespielt (Triumphales Motiv der Blechbläser

86 Plessner 2003 (1945), S. 332.

87 Plessner 2003 (1945), S. 331. 
zum eingeblendeten Regisseurnamen „Howard Hawks“) und in eine einheitliche Klangkomposition gebracht, so dass sie weniger in Konkurrenz zueinander wie vorher (gegenseitiges Unterbrechen), sondern als harmonische Einheit erlebbar sind.

Sehr unterschiedliche musikalische Motive werden nacheinander kurz angespielt, dazu erfolgt ein rascher Wechsel von Tempo, Rhythmus und unterschiedlichen Klangfarbe durch sich ändernde Instrumentierung: Wie im Wettstreit unterbrechen sich das Romantische, das Triumphale und das Beschwingte, um am Ende in einer einheitlichen Klanggestalt aufzugehen.

Das schon für die Gesten und Stimmen anderer Szenen aufgezeigte, charakteristische Inszenierungsprinzip einer ,Gegensinnigkeit als Einheit* (Plessner ${ }^{88}$ ) scheint hier am Anfang des Films bereits auf. Dadurch bereitet der Film bereits ein poetologisches Prinzip vor, das er später vollends ausspielen wird: die Inszenierung eines widerstreitenden Paares oder einer höchst disparaten Gruppe, in der jeder durcheinander spricht, ${ }^{89}$ wobei sich am Ende alles zu einer Einheit fügt. Eine solche Einheit ist nicht mehr auf der Ebene des Dargestellten zu verorten. Die Einheit ist das Gefühl, das sich allein in der Zuschauererfahrung realisiert.

\subsection{Ausklang}

Das Kapitel fokussierte zwei Bildtypen, die für die Screwball Comedy paradigmatisch sind: das gewöhnliche und das posierende Gesicht. Beide Formen stellen die Gesichtsbilder in eine Kommunikationsfunktion. Dadurch werden die Gesichter zu Elementen einer Interaktion, die nicht mehr zwischen dargestellten Figuren - wie von außen betrachtet - ausgeführt wird, sondern die, bestehend aus Worten, Bildformationen, Stimmklängen, Gesten und Mimiken, eine audiovisuelle Kommunikation mit dem Zuschauer eingeht. Die beiden Gesichtsbild-Typen realisieren sich dabei in spezifischen Zeitmustern, die an die Montage gebunden sind und die zwei Schauspieler als Paar erscheinen lassen.

Neben diesen Bildtypen, welche die Screwball Comedy ausprägt, wurde außerdem untersucht, auf welche Weise man von Figurengefühlen sprechen kann. Dabei wurde anhand einer Szene aus THE AWFUL TRUTH erörtert, wie auf der Basis

88 Eine „Gegensinnigkeit, die gleichwohl als Einheit sich vorstellt“ Plessner 2003 (1945), S. 294.

89 Hawks' Screwball Comedies sind dafür bekannt, dass sich die Schauspieler nicht ausreden lassen, sondern sich unterbrechen, gleichzeitig sprechen und die Sätze überlappen. Brian Wilson: The Film Dialogue of Howard Hawks. In: Jeff Jaeckle (Hg.): Film Dialogue. New York 2013, S. 116-125, hier S. 122. 
von Tempogestaltungen in der Montage ein Verstehensprozess in Gang gesetzt wird. Dieser Prozess beinhaltet das Erleben verschiedener Kräfte, die aus der kinematografischen Bewegung kommend die Zuschauerwahrnehmung prägen, aber auf die Schauspielerkörper bezogen werden. Einen solchen Fiktionalisierungsprozess habe ich über den Akt der Metaphorisierung rekonstruiert: Figuren werden erst auf der Basis eines verkörperten Erfahrens als solche konstruiert bzw. fiktionalisiert.

Wie verschiedene Gefühlsmodi sich in der Komödienerfahrung ausprägen, wurde am Ende des Kapitels erörtert. Dabei wurde ein poetologisches Prinzip aufgezeigt, mit dem bestimmte Gefühlsbereiche angesprochen, aber sogleich wieder abgewandelt werden. Die Komödie ist als ein Wechselspiel oft gegensätzlicher Gefühlsmodi zu beschreiben, welche in ihrer Kürze selten gänzlich zur Entfaltung kommen, sondern immer nur angespielt, begonnen und dann abgebrochen bzw. transformiert werden. Die die punktuellen Stimmungen überspannende Gefühle finden sich im heiteren Register angesichts einer sichtbaren und hörbaren Lebendigkeit. 